UNIVERSIDADE DE SÃO PAULO

ESCOLA DE ENFERMAGEM

FERNANDA DE OLIVEIRA ANDRADE

INFECÇÃO DO SÍTIO CIRÚRGICO E O USO DE TOALHAS IMPREGNADAS COM GLUCONATO DE CLOREXIDINA $2 \%$ NO PREPARO PRÉ-OPERATÓRIO DA PELE: ENSAIO CLÍNICO RANDOMIZADO - ESTUDO PILOTO

São Paulo

2018 


\title{
INFECÇÃO DO SÍTIO CIRÚRGICO E O USO DE TOALHAS IMPREGNADAS COM GLUCONATO DE CLOREXIDINA 2\% NO PREPARO PRÉ-OPERATÓRIO DA PELE: ENSAIO CLÍNICO RANDOMIZADO - ESTUDO PILOTO
}

\begin{abstract}
Versão corrigida da Dissertação apresentada ao Programa de PósGraduação em Enfermagem na Saúde do Adulto da Escola de Enfermagem da Universidade de São Paulo para obtenção do título de Mestre em Ciências.
\end{abstract}

Área de Concentração: Enfermagem na Saúde do Adulto

Orientadora: Prof. ${ }^{\underline{a}}$ Dr. ${ }^{\underline{a}}$ Vanessa de Brito Poveda

\section{VERSÃO CORRIGIDA}

A versão original encontra-se disponível na Biblioteca da Escola de Enfermagem da Universidade de São Paulo e na Biblioteca Digital de Teses e Dissertações da Universidade de São Paulo.

São Paulo

2018 
AUTORIZO A REPRODUÇÃO E DIVULGAÇÃO TOTAL OU PARCIAL DESTE TRABALHO, POR QUALQUER MEIO CONVENCIONAL OU ELETRÔNICO, PARA FINS DE ESTUDO E PESQUISA, DESDE QUE CITADA A FONTE.

Assinatura:

Data:

\section{Catalogação na Publicação (CIP)}

Biblioteca "Wanda de Aguiar Horta"

\section{Escola de Enfermagem da Universidade de São Paulo}

Andrade, Fernanda de Oliveira

Infecção do sítio cirúrgico e o uso de toalhas impregnadas com gluconato de clorexidina $2 \%$ no preparo pré-operatório da pele: ensaio clínico randomizado - estudo piloto / Fernanda de Oliveira Andrade. São Paulo, 2018.

$96 \mathrm{p}$.

Dissertação (Mestrado) - Escola de Enfermagem da Universidade de São Paulo.

Orientadora: Prof. ${ }^{a}$ Dr. ${ }^{\underline{a}}$ Vanessa de Brito Poveda

Área de concentração: Enfermagem na Saúde do Adulto

1. Infecção da ferida operatória. 2. Período pré-operatório. 3. Enfermagem perioperatória. 4. Clorexidina. 5. Antissepsia. I. 
Nome: Fernanda de Oliveira Andrade

Título: Infecção do sítio cirúrgico e o uso de toalhas impregnadas com gluconato de clorexidina $2 \%$ no preparo pré-operatório da pele: ensaio clínico randomizado - estudo piloto

Aprovado em:

\section{Banca Examinadora}

Profo.Dr. ${ }^{\circ}:$ Instituição:

Julgamento:

Assinatura:

Profo.Dr. ${ }^{\circ}:$ Instituição:

Julgamento:

Assinatura:

Prof ${ }^{\circ}$.Dr. ${ }^{\circ}$ : Instituição:

Julgamento: Assinatura: 


\section{Dedicatória}

À minha mãe Angela (in memoriam), meu exemplo de vida e pessoa, minha inspiração; sem você, a realização deste sonho não seria possivel. Te amo.

A minha tia Maria das Graças, pelo apoio e incentivo incondicional em todos os momentos. Sou imensamente grata a Deus por sua presença em minha vida. 


\section{Agradecimentos}

Em primeiro lugar agradeço a Deus, qve iluminou o mev caminho, pois sem Ele ev não teria forças para essa longa jornada.

Às minhas tias Ana Maria, Maria Aparecida e Maria das Graças, por serem pessoas maravilhosas e sempre presentes em minha vida.

Às minhas afilhadas Rakel, Ana Júlia e Emanuelle, bênçãos de Deus em minha vida.

Às minhas primas Graziele, Caroline e em especial Francieli, agradeço imensamente por todo o apoio e carinho, e por levar meus documentos à EEUSP quando eu não podia ir.

À Profa. Dra. Vanessa de Brito Poveda, pela sua disponibilidade, paciência na orientação e incentivo, que tornaram possível a conclusão desta dissertação.

Às minhas ex-chefes do Hospital Santa Casa de Londrina, Ir. Lorena Jenal e Eliane Emandes, onde tudo começou. Agradeço pela confiança, incentivo ao estudo e liberação para cursar o mestrado.

Às minhas chefias imediatas $\mathcal{N a d j a , ~ J u l i a n a ~ e ~ T a ̂ n i a , ~ p e l a ~ c o m p r e e n s a ̃ o , ~}$ cooperação, apoio e liberação para as aulas do mestrado.

À chefe da unidade cirúrgica Silvana, pelo apoio, carinho e preocupação com a minha dissertação. pesquisa.

Aos pacientes, por disponibilizarem seu tempo e aceitarem participar da

Ao hospital e toda a equipe de enfermagem, por autorizarem a pesquisa $e$ contribuírem para a sua execução.

Às empresas Politec Saúde e Rioquímica, pela doação dos produtos, parte primordial para a execução e desenvolvimento desta pesquisa. 
"Tudo posso naquele que me fortalece" Filipenses 4:13 
Andrade, FO. Infecção do sítio cirúrgico e o uso de toalhas impregnadas com gluconato de clorexidina $2 \%$ no preparo pré-operatório da pele: ensaio clínico randomizado - estudo piloto. [Dissertação]. São Paulo: Escola de Enfermagem, Universidade de São Paulo; 2018.

\section{RESUMO}

Introdução: As infecções do sítio cirúrgico (ISC) são um dos principais eventos adversos evitáveis no perioperatório, ocasionando danos econômicos, físicos e emocionais aos pacientes acometidos. Nesse contexto, o uso de antissépticos no pré-operatório reduz a contagem microbiana da pele, podendo contribuir para a prevenção da ISC. Evidências internacionais apontam que as toalhas impregnadas com gluconato de clorexidina ( $\mathrm{CHG}$ ) $2 \%$ destacam-se por sua praticidade e efeito residual superior. No Brasil, no entanto, não existem estudos relacionados à utilização do produto para a redução da contagem microbiana de pele no pré-operatório. Objetivo: Comparar o uso das toalhas impregnadas com CHG $2 \%$ ao banho pré-operatório tradicional com CHG $2 \%$ convencional/líquida na prevenção da ocorrência da ISC entre pacientes submetidos a cirurgias eletivas potencialmente contaminadas. Método: Tratase de um estudo piloto de ensaio clínico randomizado controlado, composto por pacientes submetidos a cirurgias eletivas potencialmente contaminadas, distribuídos aleatoriamente em grupo intervenção $(n=23)$, constituído pelos que utilizaram as toalhas impregnadas com $\mathrm{CHG} 2 \%$ no pré-operatório, e grupo controle ( $n=22)$, composto pelos submetidos ao banho pré-operatório com $\mathrm{CHG}$ $2 \%$ convencional/líquida. Ambos utilizaram os produtos na noite anterior e na manhã da cirurgia e receberam orientações verbais e por escrito. Resultados: Os pacientes não apresentaram diferenças em relação às características clínicas e cirúrgicas. Não foram observadas diferenças estatísticas significativas entre os grupos intervenção e controle quanto à redução na ocorrência de ISC $(p=1,000)$. Conclusão: Não houve diferença entre os grupos intervenção e controle quanto à ocorrência de ISC.

PALAVRAS-CHAVE: Infecção da ferida cirúrgica. Período pré-operatório. Enfermagem perioperatória. Clorexidina. Antissepsia. 
Andrade, FO. Surgical site infection and the use of $2 \%$ chlorhexidine gluconate impregnated cloth bathing in preoperative skin preparation: a pilot randomized clinical trial [Thesis]. São Paulo: Escola de Enfermagem, Universidade de São Paulo; 2018.

\begin{abstract}
Introduction: Surgical site infections (SSI) are described as evitable perioperative adverse effect, affected patients suffer economic, physical, and emotional harm. Preoperative antiseptics use reduces skin microbial counts and prevention SSI. International evidences suggest that $2 \%$ chlorhexidine gluconate (CHG) impregnated cloth bathing are practical and presents a superior residual effect. However, in Brazil no studies related to the use of this product for the reduction of skin microbial count in perioperative were conducted. Objective: To compare the use of $2 \%$ chlorhexidine gluconate impregnated cloth bathing to the traditional preoperative $2 \% \mathrm{CHG}$ standard/liquid bathing to prevent SSI incidence in patients submitted to cleancontaminated electives surgeries. Method: Pilot randomized clinical trial conducted with patients submitted to potentially contaminated electives surgeries. They were randomly distributed in intervention group $(n=23)$ that used the $2 \% \mathrm{CHG}$ impregnated cloth bathing in the preoperative, and control group ( $n=22$ ) that was submitted to the standard/ liquid preoperative $2 \%$ CHG. Both groups used the products in the previous night and morning of the surgery, and received verbal and written orientation. Results: The patients did not present differences related to clinical and surgical features. No statistical differences between intervention and control groups were observed concerning the reduction of $S S I(p=1,000)$. Conclusion: There were no differences between intervention and control groups concerning ISC reduction.
\end{abstract}

KEYWORDS: Surgical wound infection. Preoperative period. Perioperative nursing. Chlorhexidine. Antisepsis. 


\section{LISTA DE ILUSTRAÇÕES}

Figura 1 - Toalhas impregnadas com gluconato de clorexidina $2 \%$............... 29

Figura 2 - Gluconato de clorexidina 2\% convencional/líquida..................... 31

Figura 3 - Fluxograma de distribuição dos pacientes participantes do estudo 43 


\section{LISTA DE QUADROS}

Quadro 1 - Critérios diagnósticos para infecções do sítio cirúrgico estabelecidos pelos Centers for Disease Control and Prevention. Curitiba, 2017. 


\section{LISTA DE TABELAS}

Tabela 1 - Características dos pacientes de acordo com as características clínicas e cirúrgicas. Curitiba, 2017.

Tabela 2 - Características cirúrgicas dos pacientes participantes do estudo. Curitiba, 2017

Tabela 3 - Características dos pacientes de acordo com o intraoperatório, antibioticoprofilaxia e antissepsia da pele. Curitiba, 2017.

Tabela 4 - Temperatura axilar, temperatura esofágica e glicemia capilar no perioperatório. Curitiba, 2017.

Tabela 5 - Topografia das infecções do sítio cirúrgico no grupo intervenção e grupo controle. Curitiba,2017.

Tabela 6 - Características dos pacientes que não desenvolveram e pacientes que desenvolveram infecção do sítio cirúrgico no grupo intervenção e no grupo controle. Curitiba, 2017. 


\section{LISTA DE ABREVIATURAS E SIGLAS}

AORN Association of Perioperative Registered Nurses

APIC Association for Professionals in Infection Control and Epidemiology

ASA Classificação do Estado Físico segundo a American Society of Anestesiologists

CC Centro Cirúrgico

CDC Centers for Disease Control and Prevention

CEP Comitê de Ética em Pesquisa

CHG Gluconato de Clorexidina

CHGL gluconato de clorexidina $2 \%$ convencional/líquida

DM Diabetes Mellitus

DP Desvio Padrão

ECR Ensaio Clínico Randomizado

GC Grupo Controle

Gl Grupo Intervenção

HAS Hipertensão Arterial Sistêmica

HTA Histerectomia Total Abdominal

ICS Infecção de Corrente Sanguínea

IH Infecção Hospitalar

IHI Institute for Healthcare Improvement

IMC Índice de Massa Corporal

IRAS Infecção Relacionada à Assistência à Saúde

ISC Infecção do Sítio Cirúrgico

ISC-IP Infecção do Sítio Cirúrgico - Incisional Profunda

ISC-IS Infecção do Sítio Cirúrgico - Incisional Superficial

ISC-OC Infecção do Sítio Cirúrgico - Incisional Órgão ou Cavidade

ITU Infecção do Trato Urinário

NISC Não apresentou Infecção do Sítio Cirúrgico

PO Pós-operatório

POI Pós-operatório Imediato

PVPI lodopovidona

REBEC Registro Brasileiro de Ensaios Clínicos

SPCIH Serviço Prevenção e Controle de Infecção Hospitalar

SPIRIT Standart Protocol Items: recommendations for interventional trials

SPSS Statistical Package for the Social Sciences

SUS Sistema Único de Saúde

TCLE Termo de Consentimento Livre e Esclarecido

TICHG Toalhas impregnadas com gluconato de clorexidina $2 \%$

UTI Unidade de Terapia Intensiva

WHO World Health Organization 


\section{LISTA DE SÍMBOLOS}

$\begin{array}{ll}{ }^{\circ} \mathrm{C} & \text { Graus Celsius } \\ \% & \text { Porcentagem } \\ \mathrm{Kg} & \text { Quilograma } \\ \mathrm{m}^{2} & \text { Metro Quadrado } \\ \mathrm{X}^{2} & \text { Qui-quadrado } \\ \mathrm{mg} / \mathrm{dl} & \text { Miligramas por decilitro } \\ \mathrm{p} & \text { Probabilidade de significância } \\ \mathrm{n} & \text { Número } \\ \mathrm{min} & \text { Minuto(s) } \\ > & \text { Maior que }\end{array}$




\section{SUMÁRIO}

1 INTRODUÇÃO

1.1 A problemática da Infecção do Sítio Cirúrgico .................................. 16

1.2 Sobre as técnicas de preparo de pele disponíveis atualmente e suas

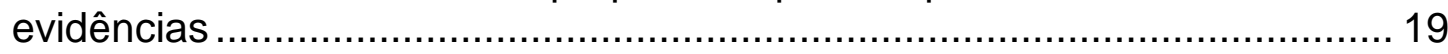

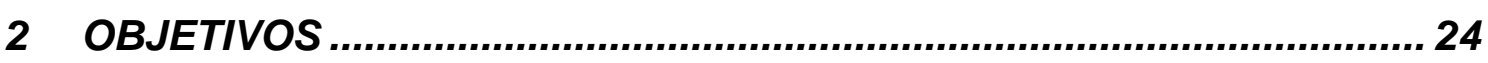

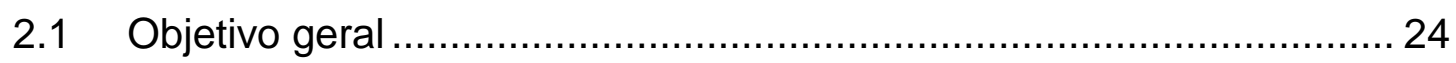

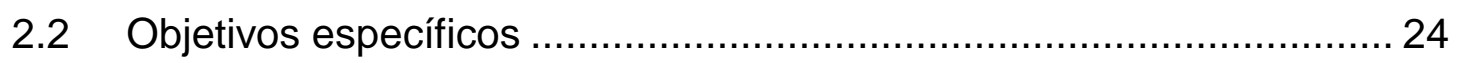

3 METODOLOGIA

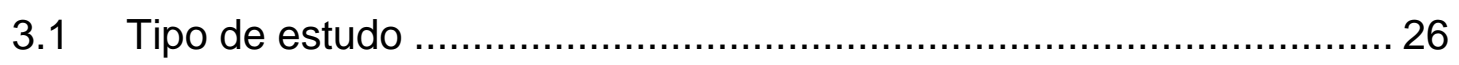

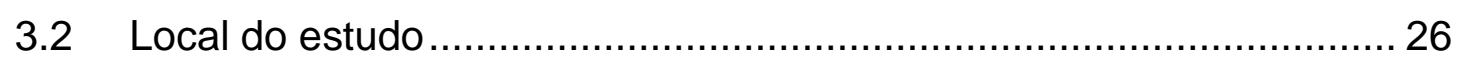

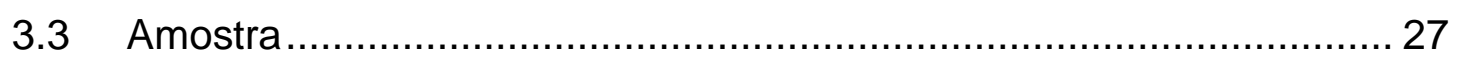

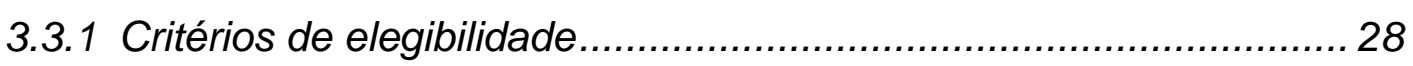

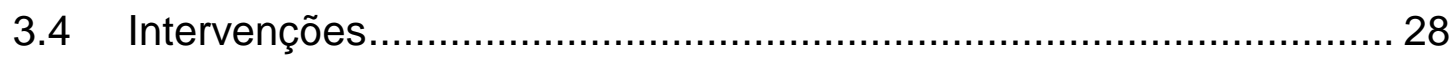

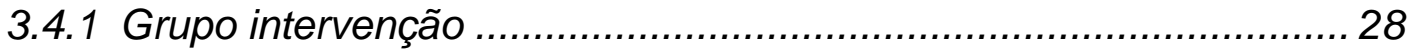

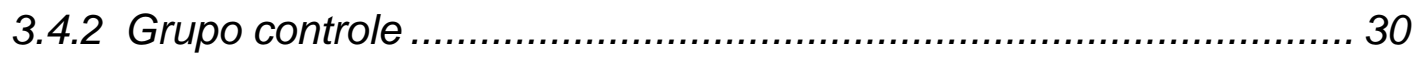

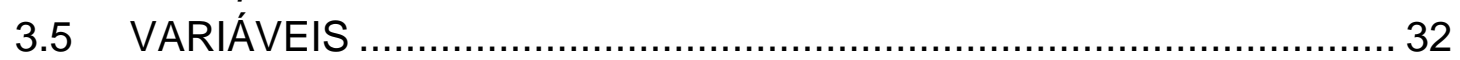

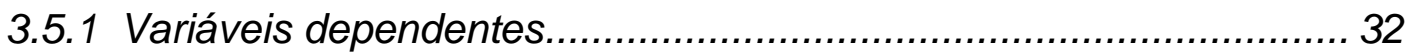

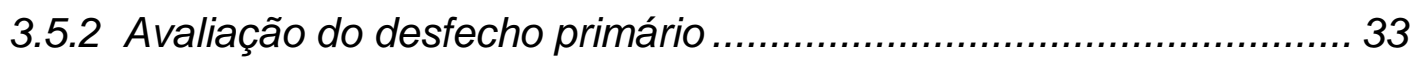

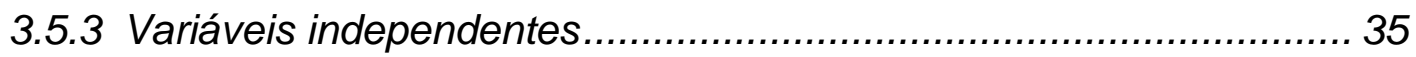

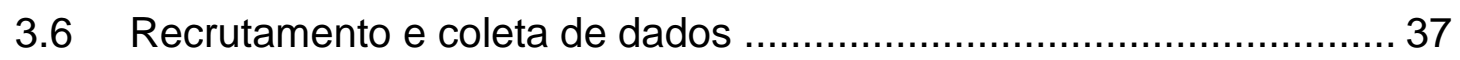

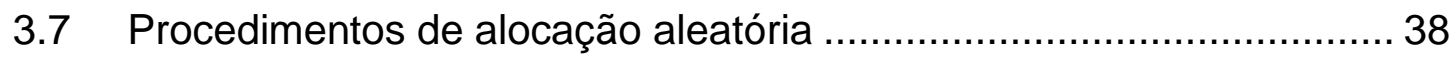

3.8 Procedimentos ético-legais e de registro do ensaio clínico .................. 38

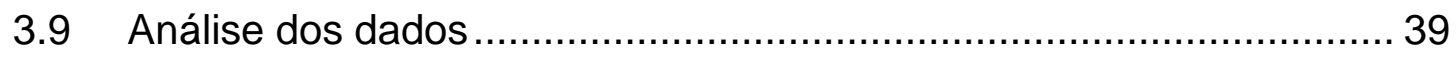

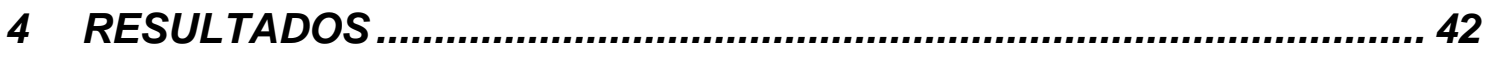

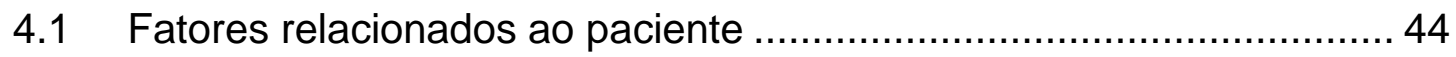

4.2 Fatores relacionados ao perioperatório ........................................... 45

4.3 Fatores relacionados às infecções do sítio cirúrgico ........................... 50

4.4 Vantagens e desvantagens do uso dos produtos antissépticos em

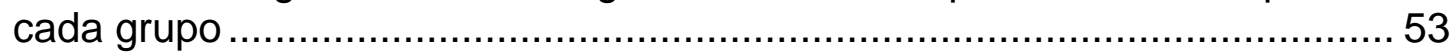

5 DISCUSSÃO

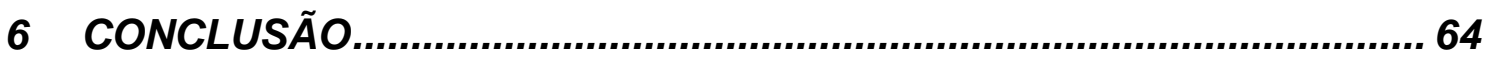

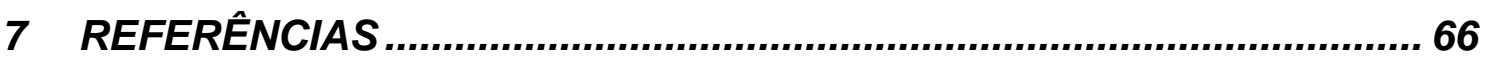

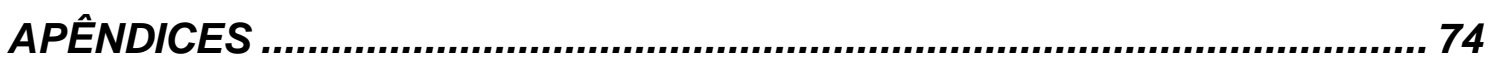

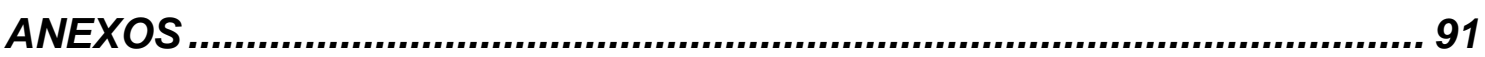


1 Introdução 


\section{INTRODUÇÃO}

\subsection{A PROBLEMÁTICA DA INFECÇÃO DO SíTIO CIRÚRGICO}

Infecção hospitalar $(\mathrm{IH})$ pode ser definida como uma complicação "adquirida na hospitalização e que não estava presente ou em incubação quando da admissão hospitalar do paciente"(1). Com a percepção de que as $\mathrm{IH}$ não são mais restritas aos ambientes hospitalares, mas podem acontecer em quaisquer outros serviços que prestavam cuidados à saúde (postos de saúde, atendimentos ambulatoriais, home care, etc.), recomenda-se atualmente a utilização do termo infecção relacionada à assistência à saúde (IRAS), por sua maior abrangência ${ }^{(2)}$.

As IRAS são complicações graves, consideradas eventos adversos persistentes nas instituições de saúde, que ameaçam a segurança do paciente e aumentam o tempo de internação, os custos no cuidado do paciente, a morbidade e a mortalidade. As IRAS atingem frequentemente alguns sítios específicos, com importância mundial e epidemiológica dentro do controle das instituições hospitalares; são elas: as infecções do sítio cirúrgico (ISC), infecções do trato urinário (ITU), infecções da corrente sanguínea (ICS) e infecções do trato respiratório(3).

No Brasil, a infecção do sítio cirúrgico (ISC) ocupa a terceira posição entre todas as infecções em instituições de saúde. Suas taxas variam de acordo com o tipo de procedimento e a gravidade da doença subjacente ${ }^{(4)}$. A ISC é considerada uma das maiores e mais importantes complicações pósoperatórias, sendo responsável por $14 \%$ a $16 \%$ de todas as IRAS em pacientes hospitalizados $^{(5)}$.

Os procedimentos cirúrgicos podem ser classificados em limpos, aqueles realizados em tecidos estéreis, sem presença de processo inflamatório; potencialmente contaminados, quando realizados em tecidos que possuem microbiota residente não numerosa em condições controladas e sem 
Fernanda de Oliveira Andrade

contaminação; contaminados, realizados em tecidos cuja microbiota é significativa, de difícil descontaminação, na presença de sinais flogísticos ou técnica asséptica inadequada; e infectados, que envolvem qualquer tecido ou órgão com presença de infecção, caracterizada por presença de pus e tecido desvitalizado(6,7). O potencial de contaminação da cirurgia afeta as taxas médias de ocorrência esperada de ISC, considera-se que até $60 \%$ das ISC são evitáveis quando adotadas medidas de prevenção em todo período perioperatório pela equipe multidisciplinar ${ }^{(8,9)}$.

Portanto, a ISC pode ser definida como aquela que ocorre após a cirurgia, acometendo a incisão e cavidades manipuladas durante 0 procedimento cirúrgico realizado. Acontece nos primeiros 30 dias após a cirurgia, ou até 90 dias se houver implante de prótese, segundo recomendação do Centers for Disease Control and Prevention ${ }^{(7)}$.

A ISC também é classificada, de acordo com sua topografia, em ISC incisional superficial (ISC-IS), ao envolver apenas pele e tecido subcutâneo; ISC incisional profunda (ISC-IP), que acomete tecidos moles e profundos à incisão; e ISC incisional órgão/cavidade (ISC-OC), quando abrange qualquer órgão ou cavidade aberta ou manipulada durante a cirurgia(5,7).

Autores correlacionam os fatores que influenciam a ISC em quatro categorias: fatores relacionados ao paciente, microrganismo, procedimento cirúrgico e ambiente ${ }^{(10,11)}$.

Diversos fatores podem ser considerados de risco para a ocorrência de ISC, dentre os quais idade superior a 50 anos, diabetes mellitus (DM), tabagismo, comprometimento imunológico, desnutrição, infecções em outras partes do corpo, tempo de internação pré e pós-operatório, duração da cirurgia superior a 90 minutos e uso de drenos ${ }^{(10,12)}$.

Pacientes considerados saudáveis têm menor chance de evoluir para uma ISC quando comparados a pacientes com doenças preexistentes, pois algumas afecções podem propiciar um ambiente favorável para a infecção se instalar e progredir(12).

As ISC estão entre as principais complicações que podem acometer os pacientes no período perioperatório, ocasionando danos reversíveis ou 
Fernanda de Oliveira Andrade

irreversíveis ${ }^{(10,13)}$, além de diversos prejuízos, como aumento do tempo de internação, reabordagem cirúrgica, limitações físicas e déficit na qualidade de

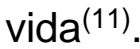

Ademais, sua ocorrência consiste em um fenômeno multifatorial, vinculado a fatores endógenos e exógenos. Sua prevenção perpassa por medidas implementadas em todo o período perioperátorio(14). Medidas baseadas em fatores considerados predisponentes ou de risco tornam-se necessárias, por meio da implementação de estratégias baseadas em evidências ${ }^{(9)}$.

Uma das estratégias atualmente empregadas tem sido a criação e implementação de pacotes de medidas preventivas conhecidos como bundles, que já se provaram eficazes na redução das ISC, quando adequadamente implantados, com envolvimento da equipe multiprofissional(13). Atualmente, as medidas de prevenção da ISC concentram-se em todo período perioperatório, incluindo ações tais como antibioticoprofilaxia, normotermia intraoperatória, controle glicêmico, oxigenoterapia, enquanto o banho pré-operatório aparece como recomendação condicional ${ }^{(7,14)}$.

$\mathrm{Na}$ maioria das cirurgias ocorre a contaminação da ferida operatória pela microbiota da pele do paciente ou do tecido operado, por instrumentais, equipe e/ou técnica cirúrgica(15).

Dessa forma, a antibioticoprofilaxia é considerada uma das estratégias para prevenção da ISC e sua eficácia está claramente comprovada quando se preserva a escolha do antibiótico apropriado, da dose adequada e a manutenção de níveis séricos e terapêuticos durante a cirurgia, reduzindo a carga microbiana que, potencialmente, pode aderir e infectar os tecidos que serão manipulados durante o procedimento cirúrgico ${ }^{(16,17)}$. Portanto, pacientes que recebem antibioticoprofilaxia 60 a 120 minutos antes da incisão cirúrgica (a depender do antibiótico escolhido) têm menos infecções do que aqueles que não a recebem ou que a recebem em tempo superior, ou, ainda, que a recebem somente após o procedimento cirúrgico ${ }^{(15,18)}$.

Por outro lado, a normotermia, definida como temperatura corporal igual ou superior a $36^{\circ} \mathrm{C}$ e inferior a $38^{\circ} \mathrm{C}$, é amplamente recomendada para 
Fernanda de Oliveira Andrade

prevenção da ISC, uma vez que pacientes cirúrgicos estão predispostos à ocorrência de hipotermia, em decorrência da inibição da termorregulação central induzida pela anestesia(11,19,20). A hipotermia é considerada fator de risco para a ISC, pois aumenta a vasoconstrição, a diminuição da oxigenação e a perfusão periférica dos tecidos, com consequente comprometimento da defesa imunológica(21).

O banho pré-operatório pode ser definido como a lavagem do corpo antes do procedimento cirúrgico, de preferência com produtos antissépticos, para finalidade higiênica e consequente redução da contagem microbiana da pele(22). Atualmente estão disponíveis novos produtos no mercado para o banho pré-operatório, o que torna fundamental analisá-los quanto a sua influência na prevenção da ISC ${ }^{(23)}$.

Para o sucesso das medidas de prevenção da ISC, faz-se necessária a adesão às ações preventivas pela equipe multidisciplinar de saúde, envolvendo também os pacientes para que estes se tornem coadjuvantes no seu tratamento(24).

É necessário o conhecimento de indicadores que subsidiem uma assistência segura e de qualidade ao paciente no pré-operatório, livre de danos $^{(25)}$, pois as ISC têm aumentado significativamente e poucas medidas novas têm sido adotadas para sua prevenção e controle ${ }^{(10)}$.

\subsection{SOBRE AS TÉCNICAS DE PREPARO DE PELE DISPONÍVEIS ATUALMENTE E SUAS EVIDÊNCIAS}

As ISC, em sua maioria, são causadas por fatores endógenos, dentre os quais se destacam microrganismos oriundos da microbiota do paciente, principalmente da pele, e também por fatores exógenos, ou seja, provenientes do ambiente(26), o que torna importante a identificação e a realização de estratégias para reduzir a colonização da pele, tendo o banho pré-operatório importância indiscutível para o êxito deste objetivo ${ }^{(27,28)}$.

Assim, o banho pré-operatório é uma das etapas do preparo cirúrgico e tem por finalidade diminuir o risco cirúrgico, por meio da redução da contagem 
Fernanda de Oliveira Andrade

microbiana da pele, atuando como coadjuvante na prevenção da ISC e, portanto, evitando complicações no período pós-operatório(29).

No entanto, as principais associações que atuam na prevenção e controle de IRAS e de atendimento ao paciente cirúrgico, como os Centers for Disease Control and Prevention (CDC), Association of Perioperative Registered Nurses (AORN), World Health Organization (WHO), ainda não emitiram recomendações conclusivas sobre o uso de solução antisséptica para o banho pré-operatório para a prevenção ou redução de ISC, devido a baixa qualidade de evidências disponíveis na literatura ${ }^{(7,18,28)}$.

A Association for Professionals in Infection Control and Epidemiology (APIC), recomenda o uso de solução antisséptica para o banho pré-operatório na noite anterior e na manhã da cirurgia, desde que padronizado e aliado à outras estratégias baseadas em evidências científicas, como medida para a redução da ocorrência da $\operatorname{ISC}^{(14)}$. Já o Institute for Healthcare Improvement (IHI) recomenda o uso de solução antisséptica para o banho pré-operatório por pelo menos três dias antes da cirurgia(30).

A antissepsia da pele utilizando agentes antissépticos, que proporciona a morte ou remoção mecânica do microrganismo, tem sido recomendada, tornando-se uma parte vital do período perioperatório(26).

Espera-se que um antisséptico ideal seja capaz de remover e/ou destruir todas as bactérias e esporos; seja atóxico; hipoalérgico; seguro para o uso em todas as regiões do corpo; não seja absorvido pela pele; tenha atividade residual; e, finalmente, seja seguro para uso repetitivo(31).

O principal produto atualmente encontrado no mercado e recomendado pela literatura para o banho pré-operatório é a clorexidina ou gluconato/diglugonato de clorexidina (CHG), uma biguanida catiônica, sintetizada em 1950, comercializada sob a forma de soluções aquosas (1\%), à base de álcool $(0,5 \%)$ ou na formulação degermante ( $2 \%$ e $4 \%$ ) e utilizada em serviços de atenção à saúde, para limpeza de mucosas, banho pré-operatório, entre outros ${ }^{(32)}$.

Alguns guias ${ }^{(14,30)}$ recomendam o uso de antissépticos para a redução da contagem de microrganismos da pele, afirmando haver benefício de sua 
Fernanda de Oliveira Andrade

utilização quando aplicados mais de uma vez, e afirmam que a antissepsia da pele é essencial para promover resultados mais eficientes na prevenção e controle de infecção em pacientes cirúrgicos.

A WHO ${ }^{(18)}$ também indica o banho pré-operatório, com sabão comum ou solução antisséptica, como medida eficaz para a redução da incidência de ISC. No entanto, não emitiu parecer conclusivo sobre a eficácia do uso de toalhas impregnadas com $\mathrm{CHG} 2 \%$ (TICHG) para o preparo pré-operatório da pele na redução da ISC, em virtude da baixa qualidade de evidências dos estudos publicados até o momento.

Coorte retrospectiva comparando 557 pacientes que utilizaram as TICHG, na noite anterior e na manhã da cirurgia, com 1.901 pacientes que tiveram apenas a antissepsia da pele na sala cirúrgica, com uma combinação de soluções (iodo $0,7 \%$ e álcool isopropílico 74\%), observou menor incidência de ISC em pacientes que utilizaram as toalhas com CHG $2 \%(0,5 \%)$ em relação ao grupo que utilizou a combinação de soluções $(1,7 \%)^{(27)}$.

Revisão sistemática recente incluindo sete ensaios clínicos randomizados, envolvendo 10.157 pacientes que utilizaram o banho préoperatório com CHG 4\% convencional/líquida, comparando-o à água e sabão ou ausência de banho, não observou uma redução estatisticamente significativa na taxa de ISC entre grupos ${ }^{(33)}$.

Ainda que os resultados desses estudos não tenham apontado diferenças estatisticamente significativas entre as intervenções, observam-se menores taxas de ISC entre os pacientes submetidos ao banho com $\mathrm{CHG}^{(34,35)}$.

Ademais, é válido ressaltar a existência de lacunas de conhecimento quanto ao número e ao tempo de banho pré-operatório com $\mathrm{CHG} 2 \%$ e a área para antissepsia da pele (local ou total) ${ }^{(28,36)}$.

Diversas recomendações giram em torno do número de aplicações necessárias do agente antisséptico na pele, parecendo haver vantagem na aplicação consecutiva(14;17). As recomendações mais atuais sugerem dois banhos pré-operatórios, um na noite anterior e outro no dia da cirurgia( ${ }^{(28)}$, o que diverge de outros achados, como a recomendação de banho com CHG 2\% por três dias consecutivos antes da cirurgia(30). 
Fernanda de Oliveira Andrade

Nesse sentido, a $\mathrm{WHO}^{(18)}$ e a $\mathrm{AORN}^{(28)}$ indicam a necessidade de estudos clínicos randomizados bem elaborados para que se possa emitir parecer conclusivo sobre o banho pré-operatório com solução antisséptica e favorecer a implementação de práticas baseadas em evidências para a redução das taxas de ISC.

Atualmente, observa-se que a maioria dos pacientes são internados no mesmo dia da cirurgia e, portanto, grande parte deles não realizam o banho pré-operatório no domicílio ou, quando o realizam, existe dificuldade em certificar-se da adequação do procedimento. Dessa forma, métodos mais rápidos e eficazes devem ser elaborados para constituir uma forma de higienização alternativa, uma vez que a microbiota da pele é responsável pela grande maioria das ISC ${ }^{(37)}$.

Mais recentemente, iniciou-se a utilização de CHG 2\% impregnada em toalhas para o banho pré-operatório. Contudo, ainda são escassas as evidências científicas relativas a esse novo material( ${ }^{(38)}$.

Acredita-se que seu uso seja mais benéfico que o banho pré-operatório tradicional, uma vez que, após sua aplicação, o produto não será removido da pele, podendo atingir e manter níveis adequados de concentração, o que seria mais eficaz na redução da contagem microbiana da pele e, portanto, na prevenção da ISC(34).

Sabe-se que, no Brasil, alguns hospitais já utilizam as TICHG; porém, até o momento, não foi encontrado na literatura nacional nenhum estudo descrevendo sua utilização ou comprovando sua eficácia em nossa realidade.

Por se tratar de um produto relativamente novo, sua utilização como ação colaborativa na prevenção de ISC precisa ser verificada e comparada a outros métodos convencionais de banho, assim como seu, custo-benefício e o modo ideal para sua utilização.

Assim sendo, a hipótese deste estudo foi comparar o uso das TICHG no preparo pré-operatório da pele com o banho tradicional com $\mathrm{CHG} 2 \%$ convencional/líquida (CHGL) na prevenção da ocorrência da ISC. 
2 Objetivos 


\section{OBJETIVOS}

\subsection{OBJETIVO GERAL}

- Comparar o uso das TICHG ao banho pré-operatório tradicional com CHGL na prevenção da ocorrência da ISC entre pacientes submetidos a cirurgias eletivas potencialmente contaminadas.

\subsection{OBJETIVOS ESPECÍFICOS}

- Comparar as taxas de ISC entre os pacientes que utilizaram o banho tradicional com CHGL e a aplicação das TICHG.

- Correlacionar a ocorrência de ISC e as variáveis relacionadas ao paciente, procedimento e o tipo de banho/preparo pré-operatório da pele.

- Identificar as dificuldades e facilidades referidas pelos pacientes na utilização das TICHG e CHGL. 
3 Metodologia 


\section{METODOLOGIA}

\subsection{TIPO DE ESTUDO}

Trata-se de um estudo piloto de uma investigação experimental, do tipo ensaio clínico randomizado (ECR) controlado, paralelo, norteado pelo Checklist: Recommended items to address in a clinical trial protocol and related documents do Standard Protocol Items: recommendations for interventional trials ${ }^{(39)}$, que buscou verificar a contribuição do uso de TICHG na prevenção da ocorrência da ISC.

Os ECR são considerados padrão-ouro para guiar nossa prática diária, representando o maior nível de evidência na avaliação da segurança e eficácia de uma determinada intervenção na área da saúde ${ }^{(40)}$, permitindo que uma hipótese testada, de forma reprodutível, responda uma questão específica, de modo que seus achados possam ser aplicados a toda população passível de receber o tratamento estudado(41).

Dessa forma, os ECR procuram isolar a contribuição de um fator testado pelo grupo intervenção, mantendo constantes, sempre que possível, os outros determinantes dos resultados, para permitir que o efeito observado seja devido à diferença na intervenção e não a outros fatores ${ }^{(42)}$. Para isso, o pesquisador intervém diretamente sobre o controle de fatores que influenciam a amostra (variáveis independentes), minimizando assim a influência de variáveis confundidoras ou intervenientes ${ }^{(43)}$.

\subsection{LOCAL DO ESTUDO}

O estudo ocorreu em um hospital universitário federal público, de nível terciário, destinado ao ensino, pesquisa e assistência, situado no Estado do Paraná, no Brasil. 
O hospital atende exclusivamente pacientes do Sistema Único de Saúde (SUS) provenientes de todo o Estado do Paraná. Possui 570 leitos, 14 salas cirúrgicas para atendimento de diversas especialidades e seis salas cirúrgicas destinadas a atendimento obstétrico. Ao todo são realizadas 540 cirurgias/mês e aproximadamente 1.300 internações ao mês.

Quanto à rotina institucional de atendimento aos pacientes cirúrgicos, após avaliação médica em regime ambulatorial, os pacientes eram agendados, conforme disponibilidade da escala cirúrgica do serviço. Por se tratar de hospital que atende à demanda de todo o Estado, em geral, os pacientes eram hospitalizados no dia anterior ou no mesmo dia da realização do procedimento cirúrgico.

Nesse período, a enfermeira avaliava a necessidade de realização de tricotomia com lâmina de barbear na noite anterior à cirurgia. A antibioticoprofilaxia era realizada na sala cirúrgica, durante a indução anestésica. Não existia nenhuma normativa institucional; a decisão do medicamento ficava a critério do cirurgião.

A antissepsia da pele foi realizada em todos os procedimentos cirúrgicos com produtos antissépticos degermantes, tópicos e/ou alcoólicos à base de iodo e/ou gluconato de clorexidina, segundo preferência do cirurgião. Os campos cirúrgicos foram de tecido esterilizado e os fluidos para infusão e irrigação utilizados em temperatura ambiente.

A antibioticoprofilaxia poderia ser continuada, a critério do médico plantonista da unidade onde o paciente seria admitido no pós-operatório imediato (POI), não seguindo protocolo instituicional.

\subsection{AMOSTRA}

Foi constituída uma amostra por conveniência, composta por 58 pacientes submetidos a cirurgias eletivas potencialmente contaminadas, em um hospital federal no Estado do Paraná, no período de maio a dezembro de 2017. 
Fernanda de Oliveira Andrade

\subsubsection{Critérios de elegibilidade}

Foram incluídos pacientes com idade igual ou superior a 18 anos, alfabetizados, submetidos a cirurgias eletivas potencialmente contaminadas, admitidos no dia anterior ao procedimento cirúrgico ou no máximo com três dias de internação anteriores à cirurgia, sem processo infeccioso ou inflamatório em outro sítio e que seguiram corretamente as instruções para o uso das TICHG (Apêndice A) e as instruções para o uso de CHGL (Apêndice B).

Foram excluídos os pacientes submetidos a cirurgias anteriores, em um período inferior a trinta dias, ou noventa dias em se tratando de implante de prótese; que apresentassem lesões de pele ou alergia conhecida à $\mathrm{CHG} 2 \%$; pacientes submetidos a cirurgias videolaparoscópicas e cirurgias por via vaginal; pacientes que fizeram uso diário de produtos que contivessem antissépticos (cremes e/ou sabonetes líquidos ou em barra contendo CHG, triclosan ou similares) na sua atividade diária; ou que tivessem consumido antibióticos ou fármacos similares duas semanas antes e durante o período da coleta de dados.

\subsection{INTERVENÇÕES}

\subsubsection{Grupo intervenção}

O grupo intervenção $(\mathrm{Gl})$ recebeu dois pacotes, cada um contendo seis TICHG (Figura 1) e um manual de instruções de como utilizá-las (Apêndice A). 
Fernanda de Oliveira Andrade

Figura 1 - Toalhas impregnadas com gluconato de clorexidina $2 \%$

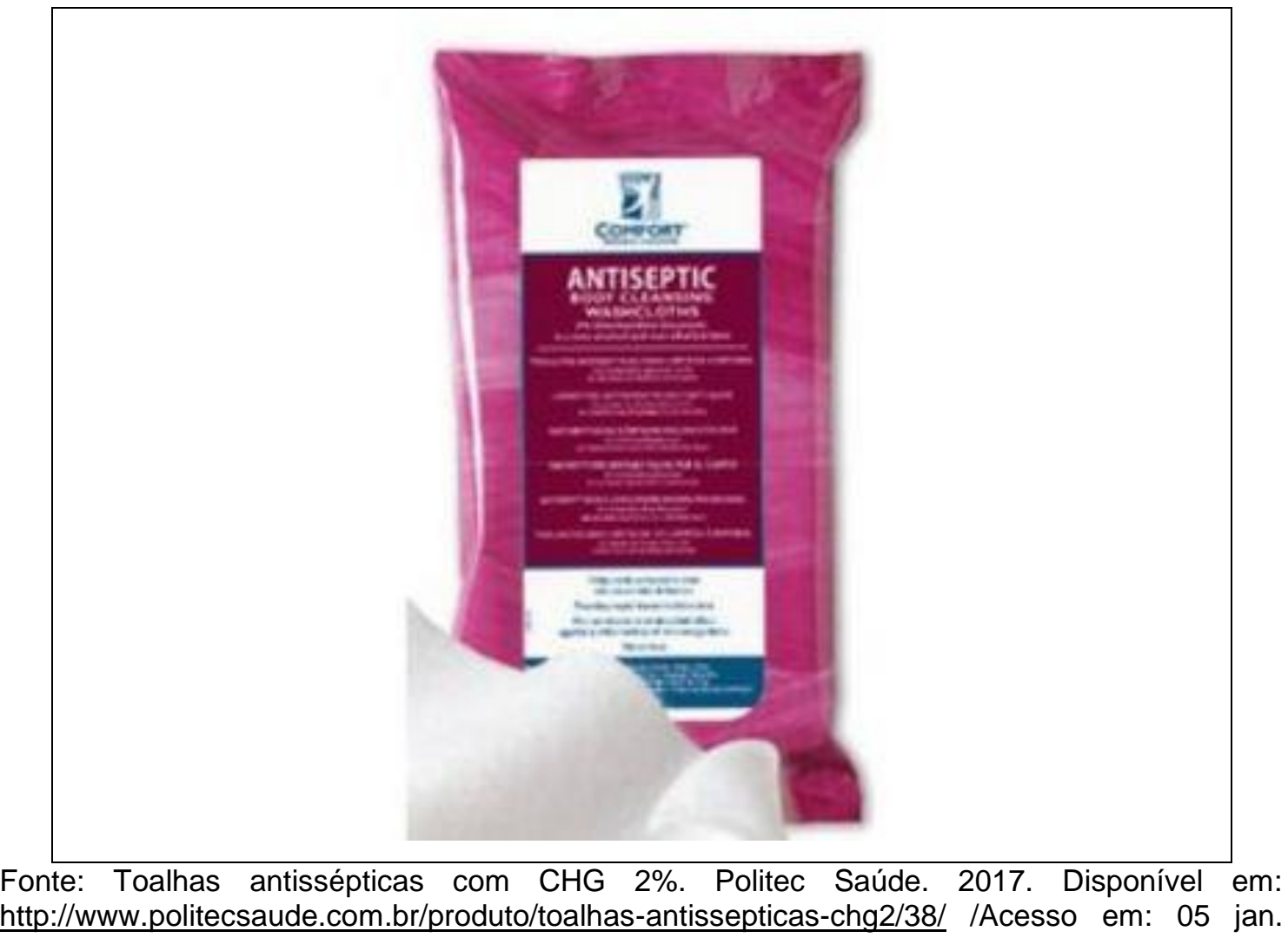
2017.

O manual de instruções orientava quanto à forma de aplicação da TICHG para garantir a similaridade de aplicação do produto entre todos os sujeitos da pesquisa.

O manual de instruções (Apêndice A) continha as seguintes informações ${ }^{(38)}$ :

1) Forma de aplicação: a primeira TICHG deveria ser utilizada no pescoço (queixo), tórax e abdome (frente); iniciar no queixo, descendo até a região suprapúbica. A segunda TICHG deveria ser usada no membro superior direito (frente e atrás); iniciar pelo ombro, descendo para o braço, antebraço, mão, entre os dedos e, por último, a axila. A terceira TICHG era destinada ao membro superior esquerdo (frente e atrás); iniciar pelo ombro, descendo para o braço, antebraço, mão, entre os dedos e, por último, a axila. A quarta TICHG deveria ser utlizada no pescoço (nuca) e tórax (atrás); iniciar na nuca, descendo até os glúteos (exceto 
região íntima). A quinta TICHG destinava-se ao membro inferior direito (frente e atrás); iniciar pela região inguinal bilateral (incluindo virilha, exceto região íntima), descendo para a perna e o pé (inclusive entre os dedos). Por fim, a sexta TICHG deveria ser usada no membro inferior esquerdo (frente e atrás); iniciar pela região inguinal bilateral (incluindo virilha, exceto região íntima), descendo para a perna e o pé (inclusive entre os dedos).

2) Momento de aplicação: utilizar seis TICHG na noite anterior à cirurgia (entre 20 e 22h) e as seis restantes na manhã da cirurgia (entre 5 e $6 h$ ).

3) Orientações gerais: não é necessário tomar banho antes da aplicação das TICHG. Caso tome banho, esperar no mínimo duas horas antes de aplicar as TICHG. Não tomar banho entre ou após a utilização das TICHG. Não utilizar bucha de banho ou qualquer outro item para esfregar o produto no corpo. Não aplicar qualquer substância na pele, como cremes, óleos, hidratantes e maquiagens, antes, entre ou após o uso das TICHG. Não utilizar o produto no rosto, cabelo e região íntima. Estar com o cabelo seco para realização da cirurgia. Aplicar as TICHG de forma que o produto seja distribuído de forma uniforme, em sentido único, em todas as partes do corpo (exceto rosto, cabelo e região íntima). Após a higienização de cada membro, descartar as TICHG. Após o uso das TICHG, esperar o produto secar na pele. Não utilizar toalhas de banho para se secar e vestir roupas limpas.

\subsubsection{Grupo controle}

Ao grupo controle (GC), foram fornecidos dois frascos de CHGL (Figura 2). Os pacientes foram orientados a realizar o banho (Apêndice $B$ ), utilizando um frasco na noite anterior à cirurgia e o outro na manhã da cirurgia ${ }^{(34)}$. 
Figura 2 - Gluconato de clorexidina 2\% convencional/líquida

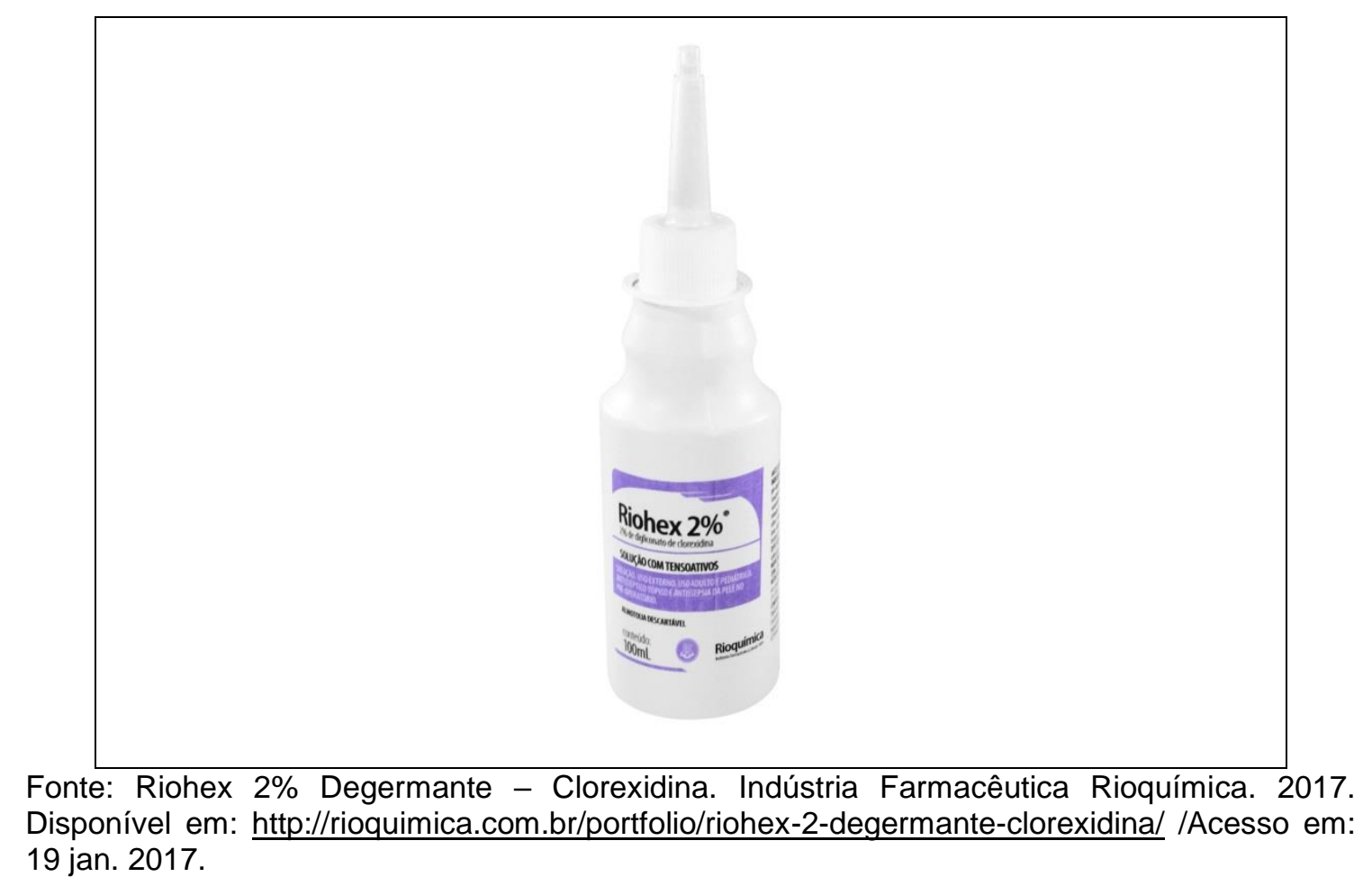

Os pacientes do GC também receberam instruções quanto à utilização do produto, com informações sobre:

1) Forma de aplicação: a CHGL deveria ser espalhada na pele durante o banho e massageada por três minutos, de forma que a distribuição fosse uniforme em todas as partes do corpo (exceto, rosto, cabelo e região íntima). Na sequência, enxaguar-se com água e secar-se com uma toalha limpa e seca.

2) Momento de aplicação: um frasco na noite anterior à cirurgia (tomar banho entre 20 e 22h) e o outro frasco na manhã da cirurgia (tomar banho entre 5 e $6 \mathrm{~h}$ ).

3) Orientações gerais: não utilizar bucha de banho ou qualquer outro item para esfregar o produto no corpo. Não utilizar outros produtos durante o banho (sabonete comum, sabão, etc.). Não aplicar qualquer substância na pele, como cremes, óleos, hidratantes e maquiagens, antes, entre ou após o banho com 
CHGL. Não utilizar o produto no rosto, cabelo e região íntima. Estar com o cabelo seco para a realização da cirurgia. Após a utilização do produto, secar o corpo com uma toalha de banho limpa e seca e vestir roupas limpas.

\subsection{VARIÁVEIS}

\subsubsection{Variáveis dependentes}

Infecções do sítio cirúrgico, segundo definição do $\operatorname{CDC}^{(7)}$, são aquelas que acometem a incisão cirúrgica, tecidos, órgãos e cavidades manipulados durante o procedimento cirúrgico, identificadas até 30 dias após a data de realização da cirurgia, quando não houver o implante de próteses. São classificadas, segundo sua topografia, como:

- ISC-IS: ocorrem até 30 dias após o procedimento e envolvem apenas pele e tecido subcutâneo. O paciente apresenta pelo menos um dos seguintes sinais e sintomas: exsudato purulento proveniente da incisão superficial, cultura positiva obtida assepticamente da incisão superficial ou tecido subcutâneo, incisão superficial deliberadamente aberta pelo cirurgião ou profissional designado com realização ou não de cultura asséptica; e pelo menos um dos sinais e sintomas: dor ou sensibilidade, edema local, eritema ou calor, diagnóstico de ISCIS realizado pelo cirurgião ou profissional designado.

- ISC-IP: ocorrem até 30 dias após o procedimento cirúrgico e envolvem tecidos moles profundos da incisão cirúrgica. $O$ paciente apresenta pelo menos um dos seguintes sinais $\mathrm{e}$ sintomas: exsudato purulento proveniente da incisão profunda, deiscência espontânea da incisão profunda ou deliberadamente abertura e drenagem da incisão profunda pelo cirurgião ou profissional designado, que permite a identificação de um 
Fernanda de Oliveira Andrade

microrganismo por meio de cultura asséptica; e pelo menos um dos sinais e sintomas: temperatura $>38^{\circ} \mathrm{C}$, dor ou sensibilidade localizada, abscesso ou outra evidência de que a infecção envolva a incisão profunda, identificados por resultado de exame histopatológico ou de imagem.

- ISC-OC: ocorrem de 30 a 90 dias após a cirurgia, em caso de implante de prótese, e envolvem qualquer órgão ou cavidade que tenha sido aberto ou manipulado durante a cirurgia. $\mathrm{O}$ paciente apresenta pelo menos um dos seguintes sinais e sintomas: exsudato purulento proveniente de um dreno localizado dentro de um órgão/cavidade, cultura positiva obtida assepticamente, abscesso ou outra evidência de infecção envolvendo órgão/cavidade, identificados por exame histopatológico ou de imagem sugestivo de infecção; e que atenda pelos menos um dos critérios do CDC para detecção de ISC-OC.

\subsubsection{Avaliação do desfecho primário}

Para a pesquisa dos potenciais casos de ISC, a pesquisadora acompanhou pessoalmente os pacientes no período de internação préoperatória (no dia anterior à cirurgia), no POI e no momento da alta hospitalar, utilizando um instrumento de coleta de dados, inspirado no material validado na dissertação de Oliveira(44) (Apêndice C). Para a avaliação da ocorrência de ISC pós-alta hospitalar, a pesquisadora utilizou as seguintes estratégias: revisão do prontuário associado a acompanhamento do paciente durante o retorno ambulatorial quando possível, que ocorreria em média no $35^{\circ}$ dia de pósoperatório; contato telefônico a partir do 30 dia até o 40ํ dia de pós-operatório (PO), utilizando instrumento de vigilância pós-alta previamente validado em

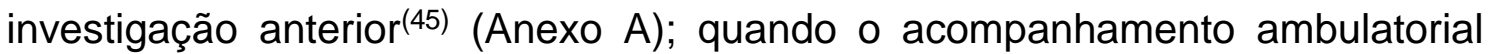
e/ou contato telefônico não era possível, utilizou-se apenas a estratégia de revisão de prontuário para a avaliação da ocorrência de ISC. 
Fernanda de Oliveira Andrade

Os dados coletados para determinar a ocorrência ou não de ISC, para os fins desta pesquisa, foram avaliados por um comitê de adjudicação, composto por três profissionais da área da saúde com experiência em vigilância, diagnóstico e tratamento de ISC, segundo os critérios propostos pelo $\operatorname{CDC}^{(7)}$ (Quadro 1). Foi respeitado o critério de maioria simples para estabelecimento da classificação ISC ou não ISC.

Quadro 1 - Critérios diagnósticos para infecções do sítio cirúrgico estabelecidos pelos Centers for Disease Control and Prevention. Curitiba, 2017.

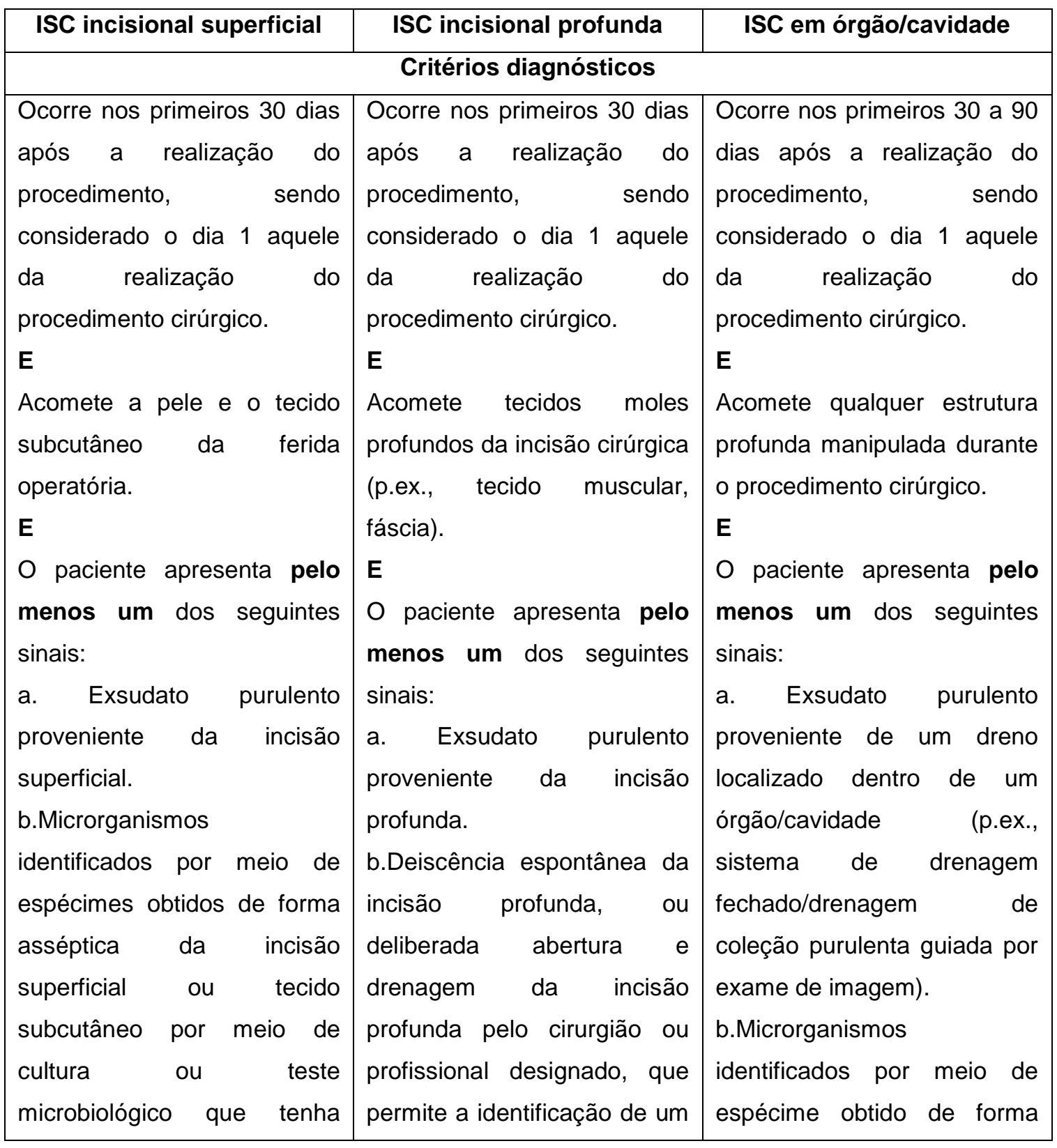


Fernanda de Oliveira Andrade

\begin{tabular}{|c|c|c|}
\hline $\begin{array}{l}\text { como objetivo o diagnóstico } \\
\text { clínico/tratamento. } \\
\text { c. Incisão superficial } \\
\text { deliberadamente aberta pelo } \\
\text { cirurgião ou profissional } \\
\text { designado com a realização } \\
\text { ou não de cultura de } \\
\text { espécime. } \\
\text { E } \\
\text { O paciente apresenta pelo } \\
\text { menos um dos sinais e } \\
\text { seguintes sintomas: dor ou } \\
\text { sensibilidade, edema local, } \\
\text { eritema ou calor } \\
\text { d. Diagnóstico de ISC } \\
\text { incisional superficial realizado } \\
\text { pelo cirurgião ou profissional } \\
\text { designado. }\end{array}$ & $\begin{array}{l}\text { microrganismo (por meio de } \\
\text { cultura ou teste } \\
\text { microbiológico que tenha } \\
\text { como objetivo o diagnóstico } \\
\text { clínico/tratamento ou a não } \\
\text { realização de cultura). } \\
\text { E } \\
\text { O paciente apresenta pelo } \\
\text { menos um dos } \\
\text { sinais/sintomas seguintes: } \\
\text { febre (T > } 38^{\circ} \text { C), dor ou } \\
\text { sensibilidade localizados. } \\
\text { (Resultado de cultura } \\
\text { negativo não atende este } \\
\text { critério.) outra } \\
\text { c. Abscesso ou oudo } \\
\text { evidência de ISC envolvendo } \\
\text { a incisão profunda (resultado } \\
\text { de exame histopatológico ou } \\
\text { de imagem). }\end{array}$ & $\begin{array}{l}\text { asséptica por meio de cultura } \\
\text { ou teste microbiológico que } \\
\text { tenha como objetivo o } \\
\text { diagnóstico } \\
\text { clínico/tratamento. } \\
\text { c. Abscesso ou outra } \\
\text { evidência de infecção } \\
\text { envolvendo órgão/cavidade, } \\
\text { identificado por exame } \\
\text { histopatológico ou resultado } \\
\text { de exame de imagem } \\
\text { sugestivo de infecção. } \\
\text { E } \\
\text { Que atenda pelo menos um } \\
\text { dos critérios do CDC para } \\
\text { detecção de infecção de sítio } \\
\text { cirúrgico em órgão/cavidade. }\end{array}$ \\
\hline
\end{tabular}

Fonte: adaptado do CDC, 2017

Todos os potenciais casos de ISC identificados durante a internação ou após a alta hospitalar foram discutidos com o SPCIH e a equipe cirúrgica responsável e encaminhados para tratamento, segundo a necessidade e trâmites correntes na instituição.

\subsubsection{Variáveis independentes}

Fatores relacionados ao paciente:

- Idade: em anos de vida

- Sexo: masculino e feminino

- DM: sim ou não

- Neoplasia: sim ou não e tipo 
- Estado nutricional: segundo índice de massa corporal (IMC)

- Tabagismo: sim ou não

Fatores relacionados ao procedimento:

- Tipo de anestesia: peridural/raquidiana + geral, raquidiana ou geral

- Duração da anestesia: em minutos

- Duração da cirurgia: em minutos

- Pessoas na sala cirúrgica: número de pessoas

- Temperatura corporal no pré-operatório, intraoperatório e PO: em ${ }^{\circ} \mathrm{C}$

- Glicemia capilar no pré-operatório, intraoperatório e PO: em mg/dl

- Tricotomia: sim ou não

- Instrumento utilizado para tricotomia: lâmina de barbear ou cera depilatória quente

- Tipo de agente antisséptico empregado no preparo intraoperatório da pele: PVPI tópica, PVPI degermante, CHG 2\% degermante ou CHG 0,5\% alcoólica

- Intercorrências durante a cirurgia: sim ou não

- Realização de antibioticoprofilaxia: sim ou não

- Antibiótico profilático administrado: cefalosporina de primeira geração e cefalosporinas de terceira geração

- Uso de hemocomponentes: sim ou não

- Tipo de hemocomponente: concentrado de hemácias

- Momento da administração do hemocomponente: pré-operatório, intraoperatório ou PO

Fatores relacionados à hospitalização:

- Tempo de internação pré-operatório, PO e total: em dias

- Uso de agentes antimicrobianos no POI: sim ou não 
Fernanda de Oliveira Andrade

- Tipo de agentes antimicrobianos no POI: cefalosporina de primeira geração e cefalosporinas de terceira geração

\subsection{RECRUTAMENTO E COLETA DE DADOS}

Inicialmente, a partir da relação diária das cirurgias e sua confirmação e admissão do paciente no hospital, a autora abordou os pacientes pessoalmente, no dia anterior à cirurgia, convidando-os a participarem e informando-Ihes a respeito dos objetivos do estudo. Caso estivessem de acordo, solicitou que assinassem o Termo de Consentimento Livre e Esclarecido (TCLE; Apêndice D).

A partir daí, dois grupos foram formados aleatoriamente: $0 \mathrm{Gl}$, caracterizado pelo uso de TICHG para o preparo pré-operatório da pele, e o GC, composto pelos pacientes submetidos ao banho pré-operatório com CHGL.

Nesse mesmo dia foram coletados os dados sociodemográficos, fatores relacionados ao paciente e ao pré-operatório (Apêndice $C$ ). A depender de sua alocação na randomização, Gl ou GC, foram entregues os produtos, com suas respectivas orientações verbais e escritas.

Na manhã da cirurgia, após a utilização dos produtos, a pesquisadora questionou os pacientes do Gl e GC se todas as orientações dos Apêndices $A$ e B haviam sido seguidas corretamente. Se a resposta fosse positiva, seguiase o acompanhamento; caso algum item não tivesse sido realizado corretamente, segundo relato do indivíduo, ele era considerado como perda de seguimento e retirado da análise final.

Ainda na manhã da cirurgia, após o uso das TICHG, os pacientes do GI foram questionados a respeito de sua opinião quanto à praticidade do produto utilizado (Apêndice E).

Após o procedimento cirúrgico, foram coletados os dados referentes aos fatores relacionados ao procedimento cirúrgico, ao pós-operatório imediato e à vigilância hospitalar (Apêndice C) e pós-alta das das ISC (Anexo A). 
Fernanda de Oliveira Andrade

Para verificar a adequação dos instrumentos e procedimentos propostos de coleta de dados, testou-se a metodologia proposta com dois pacientes que atendiam aos critérios de elegibilidade do estudo, não incluídos na análise final. Após a finalização desta etapa, foram realizadas modificações nos instrumentos, em relação à organização dos itens, e acréscimo de informações, tais como tempo de permanência na sala de recuperação pós-anestésica e local de admissão no POI.

\subsection{PROCEDIMENTOS DE ALOCAÇÃO ALEATÓRIA}

A randomização foi realizada pelo site random.org. A seguir, a sequência gerada foi lacrada em envelopes opacos numerados sequencialmente. Todo o procedimento de randomização foi realizado por indivíduo não envolvido diretamente na coleta de dados.

Os envelopes contendo a sequência de randomização foram abertos apenas no momento da decisão de alocação do sujeito participante entre os grupos de estudo. Não foi permitido aos pacientes troca de grupo após a alocação.

\subsection{PROCEDIMENTOS ÉTICO-LEGAIS E DE REGISTRO DO ENSAIO CLÍNICO}

Para a realização deste estudo, foram seguidas as Diretrizes e Normas Regulamentadoras de Pesquisas envolvendo seres humanos, emanadas da Resolução no 466 de 2012 do Conselho Nacional de Saúde(46).

O projeto foi aprovado pelo Comitê de Ética e Pesquisa (CEP) da Escola de Enfermagem da Universidade de São Paulo (instituição proponente) sob o Parecer no 2.157.183 (CAAE n 65131617.5.0000.5392) (Anexo B), após a autorização do CEP do Hospital de Clínicas da Universidade Federal do Paraná (instituição coparticipante).

Todos os pacientes foram consultados sobre sua concordância em participar da investigação e assinaram o TCLE (modelo da instituição 
coparticipante) (Apêndice D) após receberem informações a respeito dos objetivos, sigilo do estudo, possibilidade de recusa, possibilidade de desistir da investigação a qualquer momento, sem nenhum tipo de prejuízo, bem como a intenção de divulgar os dados em âmbito acadêmico e assistencial.

O ensaio clínico foi registrado no Registro Brasileiro de Ensaios Clínicos (REBEC), plataforma para registro de estudos em seres humanos conduzidos em todo o território nacional por pesquisadores brasileiros e estrangeiros, sob número de identificação RBR-8httxs.

\subsection{ANÁLISE DOS DADOS}

Para análise dos dados foi construído um banco de dados no software Microsoft Excel (2013), submetido a dupla digitação para promover segurança e qualidade dos dados.

Posteriormente, os dados foram exportados para o software Statistical Package for the Social Sciences (SPSS) e foram analisados com auxílio de um profissional estatístico.

As variáveis quantitativas, contínuas e discretas (idade, IMC, tempo de hospitalização pré-operatória, tempo de anestesia, tempo total de cirurgia, pessoas na sala cirúrgica, tempo total de hospitalização $\mathrm{PO}$, valores de glicemia e temperatura no pré-operatório, intraoperatório e $\mathrm{PO}$ ) foram avaliadas por meio do teste de Wilcoxon-Mann-Whitney.

As variáveis qualitativas (categóricas) como sexo, DM, hipertensão arterial sistêmica (HAS), tabagismo, neoplasia, classificação ASA, tricotomia, antibioticoprofilaxia no pré-operatório e no $\mathrm{POI}$, instalação de drenos, administração de hemocomponentes, antissepsia da pele, intercorrências no intraoperatório, local de admissão no $\mathrm{POI}$, foram avaliadas por meio do teste $\mathrm{X}^{2}$ Pearson.

Para as variáveis qualitativas (categóricas) como ex-tabagismo, tipo de anestesia, cuja distribuição era diferente da normal, foi utilizado o teste de Wilcoxon-Mann-Whitney. 
Fernanda de Oliveira Andrade

A topografia das ISC, assim como a interação entre as variáveis dependentes e independentes e a ocorrência de ISC por grupo, foi realizada por meio do teste exato de Fisher.

Foi realizada análise quantitativa e de conteúdo das respostas ao questionário de satisfação em relação ao produto (Apêndice E).

Para todas as variáveis, o nível de significância adotado foi de $\alpha=0,05$. 
4 Resultados 


\section{RESULTADOS}

Durante o período de coleta deste estudo piloto do tipo ECR controlado, 58 pacientes foram considerados elegíveis segundo os critérios de inclusão e exclusão propostos. No entanto, houve perdas de seguimento, e apenas 45 pacientes concluíram o estudo e foram analisados, sendo 23 alocados no Gl (TICHG) e 22 pacientes alocados no GC (CHGL), submetidos a cirurgias eletivas potencialmente contaminadas, no período de maio a dezembro de 2017, em um hospital universitário federal público situado no Estado do Paraná (Figura 3). 
Fernanda de Oliveira Andrade

Figura 3 - Fluxograma de distribuição dos pacientes participantes do estudo

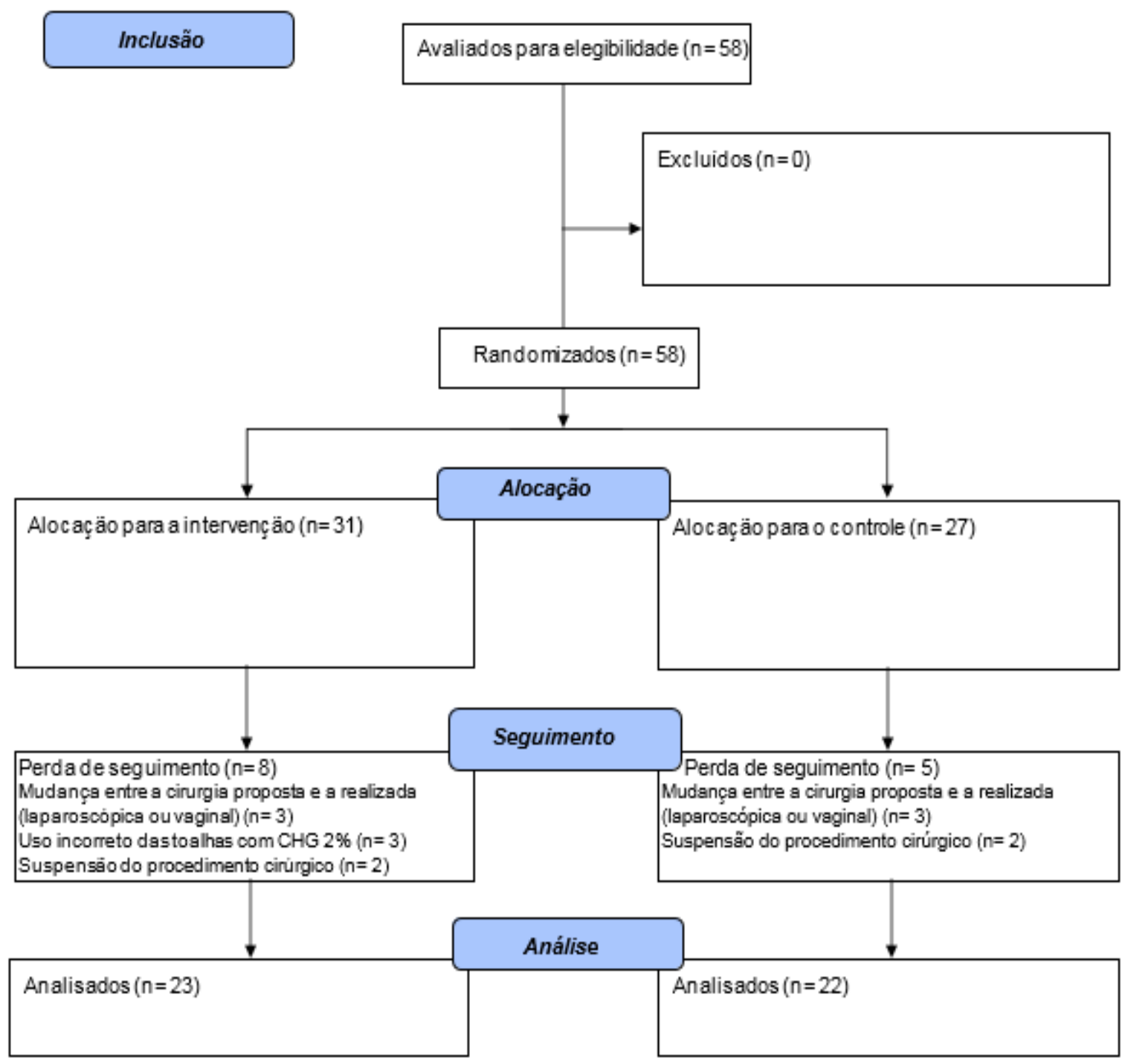


Fernanda de Oliveira Andrade

Os resultados serão apresentados segundo os fatores relacionados ao paciente, ao perioperatório, às infecções do sítio cirúrgico e às vantagens e desvantagens do uso dos produtos.

\subsection{FATORES RELACIONADOS AO PACIENTE}

Dos 45 pacientes analisados, 39 (86,7\%) eram do sexo feminino e seis $(13,3 \%)$ do sexo masculino. Houve predominância do sexo feminino 23 (100\%) no $\mathrm{GI}(\mathrm{p}=0,007)$ (Tabela 1$)$.

A idade média entre os grupos foi semelhante, sendo 46,6 anos (DP 9,7) no Gl e 47,3 anos (DP 12,3) no GC. Da mesma forma, a média de IMC obtida no $\mathrm{Gl}\left(37,2 \mathrm{~kg} / \mathrm{m}^{2}\right)$ e no GC $\left(33,9 \mathrm{~kg} / \mathrm{m}^{2}\right)$ foi similar (Tabela 1$)$.

Dos pacientes investigados, $13(28,9 \%)$ apresentavam DM e $27(60 \%)$ HAS. Em relação ao histórico de uso de tabaco, 29 (64,4\%) dos pacientes negaram tabagismo, quatro (8,9\%) relataram ser tabagistas e $12(26,7 \%)$ extabagistas.

No total, nove pacientes (20\%) apresentaram diagnóstico de neoplasias, sendo três $(13 \%)$ no Gl e seis $(27,3 \%)$ no GC. Dentre as neoplasias diagnosticadas encontravam-se as ginecológicas, gastrointestinais e urológicas.

Em relação ao diagnóstico pré-operatório: obesidade (GI: 11; 47,8\% e GC: 10; 42,9\%), doenças ginecológicas (Gl: 10; 43,4\% e GC: sete; 33,4\%), neoplasias ginecológicas (Gl: um; 4,3\% e GC: dois; 9,6\%), neoplasias gastrointestinais (Gl: um; 4,3\% e GC: um; 4,8\%), neoplasias urológicas (GC: 1; $4,8 \%$ ) e não informado (GC: um; $4,8 \%$ ). 
Fernanda de Oliveira Andrade

Tabela 1 - Características dos pacientes de acordo com as características clínicas e cirúrgicas. Curitiba, 2017

\begin{tabular}{|c|c|c|c|}
\hline Variáveis & $\begin{array}{c}\text { Grupo } \\
\text { Intervenção } \\
(n=23)\end{array}$ & $\begin{array}{c}\text { Grupo } \\
\text { Controle } \\
(n=22)\end{array}$ & $\mathbf{P}$ \\
\hline Idade (anos), média (DP) & $46,6(9,7)$ & $47,3(12,3)$ & $0,910^{*}$ \\
\hline IMC, $\mathbf{k g} / \mathrm{m}^{2}$, média (DP) & $37,2(9,3)$ & $33,9(8,8)$ & $0,159^{*}$ \\
\hline Sexo & & & $0,007^{* *}$ \\
\hline Feminino, n (\%) & $23(100)$ & $16(72,7)$ & \\
\hline Masculino, n (\%) & 0 & $6(27,3)$ & \\
\hline \multicolumn{4}{|l|}{ Comorbidades } \\
\hline HAS, n (\%) & $15(65,2)$ & $12(54,5)$ & $0,465^{\star *}$ \\
\hline $\mathrm{DM}, \mathrm{n}(\%)$ & $7(30,4)$ & $6(27,3)$ & $0,815^{\star *}$ \\
\hline Tabagismo, n (\%) & 0 & $4(18,2)$ & $0,089^{* *}$ \\
\hline Ex-tabagismo, n (\%) & $6(26,1)$ & $6(27,3)$ & $0,226^{*}$ \\
\hline Diagnóstico pré-operatório & & & $0,823^{* * *}$ \\
\hline Obesidade, $\mathrm{n}(\%)$ & $11(47,8)$ & $10(42,9)$ & \\
\hline Doenças Ginecológicas, n (\%) & $10(43,4)$ & $7(33,4)$ & \\
\hline Neoplasias Ginecológicas, n (\%) & $1(4,3)$ & $2(9,6)$ & \\
\hline Neoplasias Gastrointestinais,n(\%) & $1(4,3)$ & $1(4,8)$ & \\
\hline Neoplasias Urológicas, n (\%) & 0 & $1(4,8)$ & \\
\hline Não informado, n (\%) & 0 & $1(4,8)$ & \\
\hline
\end{tabular}

${ }^{\star}$ Teste de Wilcoxon-Mann-Whitney; ${ }^{* \star} \mathrm{X}^{2}$ de Pearson; ${ }^{* * \star}$ Teste exato de Fisher

IMC: índice de massa corporal; HAS: hipertensão arterial sistêmica; DM: diabetes mellitus

\subsection{FATORES RELACIONADOS AO PERIOPERATÓRIO}

Os $45(100 \%)$ pacientes incluídos na amostra estiveram internados em enfermaria antes de serem encaminhados para o centro cirúrgico (CC).

O tempo médio de hospitalização pré-operatória foi semelhante no $\mathrm{Gl}$ e GC, sendo, respectivamente, igual à média de 1 dia (DP 0,209) e média de 1,2 dia (DP 0,883) (Tabela 2). 
Fernanda de Oliveira Andrade

A tricotomia foi realizada por $23(51,1 \%)$ dos pacientes (Gl: $11 ; 47,8 \%$ e GC: $12 ; 54,5 \%$ ) (Tabela 2). Com relação ao instrumento utilizado para o procedimento, 20 (44,4\%) utilizaram a lâmina de barbear e três $(6,7 \%)$ usaram cera depilatória quente. Cabe destacar que, entre eles, 21 (46,7\%) realizaram a tricotomia em seu domicílio, independentemente de orientação de profissional da área da saúde, e dois (4,4\%) a realizaram no ambiente hospitalar.

Em relação à classificação pelo escore ASA, a maioria dos pacientes 24 (53,3\%) foram classificados como ASA II (GI: 10; 43,5\% e GC: 14; 63,6\%), seguidos por 16 (35,6\%) classificados como ASA III (GI: 10; 43,5\% e GC: seis; $27,3 \%$ ) e apenas cinco (11,1\%) foram classificados como ASA I (Gl: três; 13\% e GC: dois; 9,1\%) (Tabela 2).

As cirurgias gastrointestinais foram os procedimentos cirúrgicos mais frequentes nos dois grupos $(21 ; 93,2 \%)$, seguidas pelas ginecológicas (19; 84,5\%). Assim, considerando-se o Gl e o GC, o mesmo padrão se manteve, a saber, as cirurgias gastrointestinais (Gl: 11; 47,8\% e GC: 10; 45,4\%), seguidas pelas ginecológicas (Gl: nove; 39,1\% e GC: 10; 45,4\%) (Tabela 2).

Quanto à anestesia, 20 (44,4\%) sujeitos foram submetidos à associação da anestesia peridural/raquiana+geral (GI: 14; 60,9\% e GC: 16; 72,7\%), seguida da anestesia raquidiana (11; 24,4\%) (Gl: sete; 30,4\% e GC: quatro; 18,2\%) (Tabela 2).

A média de duração da anestesia foi de 206,5 minutos (Gl: 202; DP 51,8 e GC: 211,1; DP 57,1) (p=0,388) (Tabela 2).

A duração média do procedimento cirúrgico foi de 167,5 minutos (Gl: 163; DP 38,5 e GC:172,7; DP 52,3) (Tabela 2).

A média de profissionais na sala cirúrgica durante o procedimento cirúrgico foi de 4,2 profissionais (DP 0,9) para o $\mathrm{Gl}$ e de quatro profissionais (DP 0,9) para o GC (p=0,488) (Tabela 2).

A administração de concentrado de hemácias foi realizada em seis $(13,3 \%)$ dos pacientes no período perioperatório (Gl: três; $13 \%$ e GC: três; 13,6\%) (Tabela 2).

Dos dispositivos instalados no centro cirúrgico, a utilização de drenos ocorreu em quatro (8,9\%) dos pacientes (GI: dois; 8,7\% e GC: dois; 9,1\%) $(p=0,963)$ (Tabela 2). 
Fernanda de Oliveira Andrade

Três (13\%) pacientes do Gl e um (4,5\%) no GC apresentaram intercorrências no intraoperatório $(p=0,317)$ (Tabela 2), destacando-se dificuldade de acesso ao local cirúrgico devido a obesidade, trauma na bexiga e êmese.

Tabela 2 - Características cirúrgicas dos pacientes participantes do estudo. Curitiba, 2017.

\begin{tabular}{|c|c|c|c|}
\hline Variáveis & $\begin{array}{c}\text { Grupo } \\
\text { Intervenção } \\
(\mathbf{n = 2 3 )}\end{array}$ & $\begin{array}{c}\text { Grupo } \\
\text { Controle } \\
(n=22) \\
\end{array}$ & $\mathbf{P}$ \\
\hline $\begin{array}{l}\text { Hospitalização } \quad \text { pré-operatória } \quad \text { (dias), } \\
\text { média (DP) }\end{array}$ & $1,04(0,209)$ & $1,27(0,883)$ & $0,269^{*}$ \\
\hline Tricotomia, n (\%) & $11(47,8)$ & $12(54,5)$ & $0,652^{\star *}$ \\
\hline Classificação ASA & & & $0,397^{* *}$ \\
\hline ASA I, n (\%) & $3(13)$ & $2(9,1)$ & \\
\hline ASA II, n (\%) & $10(43,5)$ & $14(63,6)$ & \\
\hline ASA III, n (\%) & $10(43,5)$ & $6(27,3)$ & \\
\hline Cirurgia realizada & & & $0,714^{* * *}$ \\
\hline Gastrointestinal, n (\%) & $11(47,8)$ & $10(45,4)$ & \\
\hline Ginecológica, n (\%) & $9(39,1)$ & $10(45,4)$ & \\
\hline Urológica, n (\%) & 0 & $1(4,5)$ & \\
\hline Ginecológica + Gastrointestinal, n (\%) & $3(12,9)$ & $1(4,5)$ & \\
\hline Tipo de anestesia & & & $0,458^{*}$ \\
\hline Peridural/Raquidiana + geral, n (\%) & $14(60,9)$ & $16(72,7)$ & \\
\hline Raquidiana, n (\%) & $7(30,4)$ & $4(18,2)$ & \\
\hline Geral, n (\%) & $2(8,7)$ & $2(9,1)$ & \\
\hline \multicolumn{4}{|l|}{ Características do intraoperatório } \\
\hline Tempo de anestesia (minutos), média (DP) & $202(51,8)$ & $211,1(57,1)$ & $0,388^{*}$ \\
\hline Tempo de cirurgia (minutos), média (DP) & $163(38,5)$ & $172,7(52,3)$ & $0,472^{*}$ \\
\hline Pessoas na sala cirúrgica, média (DP) & $4,2(0,9)$ & $4(0,9)$ & $0,488^{*}$ \\
\hline Concentrado de hemácias, n (\%) & $3(13)$ & $3(13,6)$ & $0,953^{* *}$ \\
\hline Drenos, n (\%) & $2(8,7)$ & $2(9,1)$ & $0,963^{* *}$ \\
\hline Intercorrências, n (\%) & $3(13)$ & $1(4,5)$ & $0,317^{* *}$ \\
\hline $\begin{array}{l}\text { Hospitalização pós-operatória (dias), } \\
\text { média (DP) }\end{array}$ & $2,7( \pm 1,4)$ & $2,4( \pm 1,0)$ & $0,429 *$ \\
\hline
\end{tabular}

*Teste de Wilcoxon-Mann-Whitney; ${ }^{* *} \mathrm{X}^{2}$ de Pearson; ${ }^{* * *}$ Teste exato de Fisher ASA = classificação do estado físico segundo a American Society of Anestesiologists. 
Fernanda de Oliveira Andrade

Antibióticos profiláticos foram administrados em 44 pacientes $(97,8 \%)$ na recepção do $\mathrm{CC}$; um paciente $(2,2 \%)$ pertencente ao $\mathrm{GC}$ não recebeu antibioticoprofilaxia. Os principais antibióticos utilizados para a realização do procedimento cirúrgico foram as cefalosporinas de primeira e de terceira geração administradas por via endovenosa (Tabela 3).

Para a antissepsia da pele no CC foram utilizadas nos pacientes predominantemente iodopovidona (PVPI) e CHG, nas formulações tópica, degermante e alcóolica. Três (6,7\%) pacientes (GI: um e GC: dois) não tinham a descrição em seus prontuários da solução antisséptica utilizada (Tabela 3).

Tabela 3 - Características dos pacientes de acordo com o intraoperatório, antibioticoprofilaxia e antissepsia da pele. Curitiba, 2017.

\begin{tabular}{|c|c|c|c|}
\hline Variáveis & $\begin{array}{c}\text { Grupo } \\
\text { Intervenção } \\
(n=23)\end{array}$ & $\begin{array}{c}\text { Grupo } \\
\text { Controle } \\
(n=22) \\
\end{array}$ & $\mathbf{P}$ \\
\hline Antibiotiprofilaxia & & & $0,469^{\star \star}$ \\
\hline Cefalosporina de primeira geração, n (\%) & $23(100)$ & $20(90,9)$ & \\
\hline Cefalosporina de terceira geração, n (\%) & 0 & $1(4,5)$ & \\
\hline Não informado & & $1(4,5)$ & \\
\hline Antissepsia da pele & & & $0,505^{\star *}$ \\
\hline PVPI degermante + PVPI tópica, n (\%) & $13(56,5)$ & $10(45,4)$ & \\
\hline PVPI tópica, n (\%) & $7(30,4)$ & $7(31,8)$ & \\
\hline PVPI degermante, n (\%) & 0 & $1(4,5)$ & \\
\hline $\mathrm{CHG} 2 \%$ degermante, $\mathrm{n}(\%)$ & 0 & $1(4,5)$ & \\
\hline $\begin{array}{l}\text { CHG } 2 \% \text { degermante + CHG 0,5\% } \\
\text { Alcoólica, } n(\%)\end{array}$ & $1(4,3)$ & 0 & \\
\hline $\begin{array}{l}\text { PVPI degermante + PVPI Tópica + CHG } \\
0,5 \% \text { alcoólica, } n(\%)\end{array}$ & 0 & $1(4,5)$ & \\
\hline PVPI tópica + CHG 0,5\% alcoólica, $n(\%)$ & $1(4,3)$ & 0 & \\
\hline Não informado & $1(4,3)$ & $2(9,1)$ & \\
\hline
\end{tabular}

${ }^{* *} X^{2}$ de Pearson

PVPI: iodopovidona; CHG: gluconato de clorexidina 
Fernanda de Oliveira Andrade

A temperatura corporal aferida por termômetro axilar estava descrita no prontuário de 44 pacientes no pré-operatório e apresentou uma média de $36,1^{\circ} \mathrm{C}$ nos dois grupos (Gl: 36,1; DP0,3 e GC: 36; DP0,3). A mesma forma de aferição foi empregada no POI e estava descrita apenas no prontuário de 34 pacientes, com temperatura média de $35,7^{\circ} \mathrm{C}$ entre os grupos (GI: 35,7; DP 0,9 e GC: 35,7 ; DP 0,7$)$. No período intraoperatório foi verificada a temperatura esofágica em apenas sete pacientes, com média de $35,8^{\circ} \mathrm{C}$ nos dois grupos (Gl: 35,8; DP 0,5 e GC: 35,9; DP 0,3) (Tabela 4).

A glicemia capilar no período pré-operatório estava descrita no prontuário de sete pacientes e apresentou uma média de $128 \mathrm{mg} / \mathrm{dl}$ nos dois grupos (Gl:138,8; DP 52,3 e GC: 101; DP 41). No intraoperatório não foi verificada em nenhum paciente de ambos os grupos e no POI estava descrita no prontuário de 13 pacientes e apresentou uma média de $184 \mathrm{mg} / \mathrm{dl}$ entre os dois grupos (Gl:199,6; DP 84,6 e GC: 159; DP 31,9) (Tabela 4).

Tabela 4 - Temperatura axilar, temperatura esofágica e glicemia capilar no perioperatório. Curitiba, 2017.

\begin{tabular}{lccc}
\hline Variáveis & $\begin{array}{c}\text { Grupo } \\
\text { Intervenção } \\
(\mathbf{n = 2 3 )}\end{array}$ & $\begin{array}{c}\text { Grupo } \\
\text { Controle } \\
(\mathbf{n = 2 2})\end{array}$ & P \\
\hline Temperatura corporal $\left({ }^{\circ} \mathbf{C}\right)$ & $36,1(0,3)$ & $36(0,3)$ & $0,185^{*}$ \\
Axilar - pré-operatório, média (DP) & $35,8(0,5)$ & $35,9(0,3)$ & $0,858^{*}$ \\
Esofágica - intraoperatório, média (DP) & $35,7(0,9)$ & $35,7(0,7)$ & $0,477^{*}$ \\
Axilar - POI, média (DP) & & & \\
Glicemia capilar (mg/dl) & $138,8(52,3)$ & $101(41)$ & $0,439^{*}$ \\
Pré-operatório, média (DP) & $199,6(84,8)$ & $159(31,9)$ & $0,464^{*}$ \\
POI, média (DP) & & & \\
\hline $\begin{array}{l}{ }^{*} \text { Teste de Wilcoxon-Mann-Whitney } \\
\text { POI: pós-operatório imediato }\end{array}$ & & &
\end{tabular}

A maioria dos pacientes dos dois grupos foram admitidos na enfermaria no POI (41; 91,1\%); apenas quatro $(8,9 \%)$ foram admitidos na Unidade de Terapia Intensiva (UTI) (GI: dois; 8,7\% e GC: dois; 9,1\%) $(p=0,963)$. Apenas os 
Fernanda de Oliveira Andrade

pacientes admitidos na UTI no POI receberam uma dose de antibioticoprofilaxia (Gl: dois; 8,7\% e GC: dois, 9,1\%) $(p=0,963)$, sendo os antibióticos administrados a cefalosporina de primeira geração e cefalosporinas de terceira geração.

\subsection{FATORES RELACIONADOS ÀS INFECÇÕES DO SÍTIO CIRÚRGICO}

Dos 45 pacientes analisados nos dois grupos, sete $(15,6 \%)$ desenvolveram o diagnóstico de ISC, sendo quatro $(17,4 \%)$ no Gl e três $(13,6 \%)$ no $G C(p=0,356)$.

Em relação à topografia da ISC nos dois grupos, a de maior incidência foi de ISC-OC (três; 6,7\%), seguida das ISC-IS (dois; 4,4\%) e ISC-IP (dois; $4,4 \%)$.

A análise dos grupos segundo topografia e sinais e sintomas apresentados pelos pacientes que desenvolveram o diagnóstico de ISC, de acordo com os critérios do $\operatorname{CDC}^{(7)}$, são apresentados na Tabela 5.

Tabela 5 - Topografia das infecções do sítio cirúrgico no grupo intervenção e grupo controle. Curitiba,2017.

(continua)

\begin{tabular}{lccc}
\hline Variáveis & $\begin{array}{c}\text { Grupo } \\
\text { Intervenção } \\
(\mathbf{n}=23)\end{array}$ & $\begin{array}{c}\text { Grupo } \\
\text { Controle } \\
(\mathbf{n}=\mathbf{2 2})\end{array}$ & $\begin{array}{c}\text { Total } \\
(\mathbf{n}=45)\end{array}$ \\
\hline ISC, $\mathbf{n}(\%)$ & $4(17,4)$ & $3(13,6)$ & $7(15,6)$
\end{tabular}

Critérios diagnósticos

ISC incisional superficial, $\mathbf{n}(\%)$

$0 \quad 2(9,1) \quad 2(4,4)$

Drenagem purulenta da incisão superficial, $\mathrm{n} \quad$ - 2

Dor, $\mathrm{n} \quad-\quad 2$

Edema, $\mathrm{n}$

Hiperemia, $\mathrm{n} \quad-\frac{2}{2}$ 
(continuação)

\begin{tabular}{lccc}
\hline ISC incisional profunda, $\mathbf{n}(\%)$ & $2(8,7)$ & 0 & $2(4,4)$ \\
Drenagem purulenta da incisão profunda, $\mathrm{n}$ & 2 & - & \\
Deiscência parcial ou total, $\mathrm{n}$ & 1 & - & \\
Febre $>38^{\circ} \mathrm{C}, \mathrm{n}$ & 1 & - & $3(6,7)$ \\
Dor ou sensibilidade local, $\mathrm{n}$ & 2 & $1(4,5)$ & 3 \\
ISC órgão ou cavidade, $\mathbf{n}(\%)$ & $2(8,7)$ & 1 & \\
Abscesso em órgão ou cavidade, $\mathrm{n}$ & 2 & & (conclusão)
\end{tabular}

As variáveis clínico-cirúrgicas segundo o desenvolvimento de ISC por grupo de estudo são apresentadas na Tabela 6.

Destaca-se que a tricotomia foi realizada em cinco pacientes que desenvolveram o diagnóstico de ISC (GI: três; 27,3\%; GC: dois; 16,7\%) (Tabela 6). Em relação ao instrumento utilizado no Gl, dois utilizaram cera depilatória quente (no domicílio) e um paciente a lâmina de barbear (no domicílio); já no GC, dois pacientes utilizaram a lâmina de barbear (um no domicílio e outro no hospital na noite anterior à cirurgia).

Houve diferenças entre os grupos em relação a utilização de drenos (GC: um; 50\%), necessidade de transfusão sanguínea (concentrado de hemácias) no POI (GC: um; 33,3\%), reabordagem cirúrgica (GI: um; 100\%) e intercorrências no intraoperatório (Gl: um; 33,3\%) (Tabela 6). Houve reinternação hospitalar (Gl: um; 100\% e GC: um; 100\%) (Tabela 6).

Nenhuma das variáveis descritas na Tabela 6 apresentou diferença estatística significativa relativa ao desenvolvimento de ISC. 
Fernanda de Oliveira Andrade

Tabela 6 - Características dos pacientes que não desenvolveram e pacientes que desenvolveram infecção do sítio cirúrgico no grupo intervenção e no grupo controle. Curitiba, 2017.

\begin{tabular}{|c|c|c|c|c|c|}
\hline \multirow[t]{2}{*}{ Variáveis } & \multicolumn{2}{|c|}{$\begin{array}{c}\text { Grupo } \\
\text { Intervenção } \\
(\mathrm{n}=23)\end{array}$} & \multicolumn{2}{|c|}{$\begin{array}{l}\text { Grupo Controle } \\
(n=22)\end{array}$} & \multirow{2}{*}{$\begin{array}{c}p \\
1,000\end{array}$} \\
\hline & $\begin{array}{l}\text { NISC } \\
(n=19)\end{array}$ & $\begin{array}{l}\text { ISC } \\
(n=4)\end{array}$ & $\begin{array}{l}\text { NISC } \\
(n=19)\end{array}$ & $\begin{array}{l}\text { ISC } \\
(n=3)\end{array}$ & \\
\hline \multicolumn{6}{|l|}{ Sexo } \\
\hline Feminino, n (\%) & $19(82,6)$ & $4(17,4)$ & $15(93,8)$ & $1(6,3)$ & 0,230 \\
\hline Masculino, n (\%) & 0 & 0 & $4(66,7)$ & $2(33,3)$ & \\
\hline \multicolumn{6}{|l|}{ Comorbidades } \\
\hline DM, n (\%) & $6(85,7)$ & $1(14,3)$ & $4(66,7)$ & $2(33,3)$ & 0,394 \\
\hline Neoplasia, n (\%) & $2(66,7)$ & $1(33,3)$ & $5(83,3)$ & $1(16,7)$ & 0,614 \\
\hline Tabagismo, n (\%) & 0 & 0 & $4(100)$ & 0 & 0,689 \\
\hline Tricotomia, n (\%) & $8(72,7)$ & $3(27,3)$ & $10(83,3)$ & $2(16,7)$ & 0,414 \\
\hline Classificação ASA & & & & & 0,107 \\
\hline ASA I & $3(100)$ & 0 & $2(100)$ & 0 & \\
\hline ASA II & $9(90)$ & $1(10)$ & $13(92,9)$ & $1(7,1)$ & \\
\hline ASA III & $7(70)$ & $3(30)$ & $4(66,7)$ & $2(33,3)$ & \\
\hline Cirurgia & & & & & 0,146 \\
\hline Gastrointestinal, n (\%) & $11(100)$ & 0 & $8(80)$ & $2(20)$ & \\
\hline Ginecológica, n (\%) & $6(66,7)$ & $3(33,3)$ & $10(100)$ & 0 & \\
\hline $\begin{array}{l}\text { Ginecológica + gastrointestinal, } n \\
(\%)\end{array}$ & $2(66,7)$ & $1(33,3)$ & $1(100)$ & 0 & \\
\hline Urológica, n (\%) & 0 & 0 & 0 & $1(100)$ & \\
\hline Anestesia & & & & & 1,000 \\
\hline Peridural/Raqui+Geral, n (\%) & $12(85,7)$ & $2(14,3)$ & $14(77,8)$ & $2(22,2)$ & \\
\hline Raquiana, n (\%) & $5(71,4)$ & $2(28,6)$ & $4(100)$ & 0 & \\
\hline Geral, n (\%) & $2(100)$ & 0 & $1(50)$ & $1(50)$ & \\
\hline Antibioticoprofilaxia & & & & & 0,430 \\
\hline $\begin{array}{l}\text { Cefalosporina de primeira geração, } \\
\mathrm{n}(\%)\end{array}$ & $19(80)$ & $4(20)$ & $18(87,5)$ & $2(12,5)$ & \\
\hline $\begin{array}{l}\text { Cefalosporina de terceira geração, } \\
\mathrm{n}(\%)\end{array}$ & 0 & 0 & 0 & $1(100)$ & \\
\hline Não realizou, n (\%) & 0 & 0 & $1(100)$ & 0 & \\
\hline Concentrado de hemácias, n (\%) & $3(100)$ & 0 & $2(66,7)$ & $1(33,3)$ & 1,000 \\
\hline Drenos, n (\%) & $2(100)$ & 0 & $1(50)$ & $1(50)$ & 0,505 \\
\hline Reabordagem cirúrgica, n (\%) & 0 & $1(100)$ & 0 & 0 & 0,156 \\
\hline Reinternação hospitalar, n (\%) & 0 & $1(100)$ & 0 & $1(100)$ & 0,290 \\
\hline Intercorrências, n (\%) & $2(66,7)$ & $1(33,3)$ & $1(100)$ & 0 & 1,000 \\
\hline
\end{tabular}


Fernanda de Oliveira Andrade

A média de hospitalização pré-operatória dos pacientes que desenvolveram o diagnóstico de ISC nos dois grupos foi de 1,1 dia (DP 0,3), e a média do tempo de hospitalização PO foi de 3,5 dias (DP 2,1). Já a média de hospitalização pré-operatória para os pacientes que não desenvolveram 0 diagnóstico de ISC foi de 1,1 dia (DP 0,6) e PO de 2,4 dias (DP 0,9).

Não houve diferença estatística significativa entre 0 tempo de hospitalização pré-operatória $(p=0,269)$ e o tempo de hospitalização pósoperatória $(p=0,429)$.

Apenas em dois casos $(4,4 \%)$ a ISC foi identificada durante a internação, sendo um no GI (ISC-OC) e outro no GC (ISC-IS). Cinco ocorrências $(11,1 \%)$ foram constatadas no período de vigilância pós-alta. Todos os casos de ISC foram reconhecidos entre o $3^{\circ}$ e o $13^{\circ}$ dia de pós-operatório.

\subsection{VANTAGENS E DESVANTAGENS DO USO DOS PRODUTOS ANTISSÉPTICOS EM CADA GRUPO}

Em relação ao custo de aquisição das soluções antissépticas na ocasião da realização desta investigação, o preço por paciente para a realização do preparo pré-operatório da pele na noite anterior e na manhã da cirurgia com TICHG foi de $R \$ 87,48 /$ paciente, e o custo por paciente da formulação CHGL foi de $R \$ 7,98 /$ paciente.

Entre as vantagens apontadas pelos pacientes na utilização das TICHG estão praticidade, capacidade de higienização, facilidade de uso (independe de ducha de banho para a utilização) e aplicação uniforme do produto. As desvantagens apontadas foram relativas a ressecamento de pele, coceira, vermelhidão e dificuldade de passar nas costas. No que se refere à utilização da $\mathrm{CHGL}$, os pacientes mencionaram as mesmas desvantagens relatadas quanto às TICHG. 
5 Discussão 


\section{DISCUSSÃO}

Considerando a carência de investigações anteriores de mesma natureza, optou-se pela realização de um estudo piloto de ECR controlado, utilizando uma amostra por conveniência, constituída por 58 pacientes aleatorizados em dois grupos, sendo que 23 do Gl e 22 do GC concluíram sua participação no estudo.

Nas análises dos resultados encontrados, o uso de TICHG para o preparo pré-operatório da pele dos pacientes não demonstrou diferença estatística significativa quanto à prevenção da ISC quando comparado ao uso de CHGL, ou seja, as intervenções parecem ser equivalentes quanto à prevenção de ISC.

Cabe destacar também que os grupos eram similares quanto às características sociodemográficas e clínicas/cirúrgicas, exceto para o sexo.

Dos 45 pacientes que analisados no estudo, 15,6\% desenvolveram ISC, com equilíbrio entre o número de casos e diferença nas topografias identificadas entre os grupos de estudo, pois não houve casos de ISC-IS no GI e não foram identificados casos de ISC-IP no GC.

Estudo de coorte retrospectivo com o objetivo de analisar os fatores de risco predisponentes para ISC em 196 prontuários de pacientes submetidos à cirurgia oncológica do trato gastrointestinal, observou taxa de ISC de $13,26 \%$, destacou-se também a maior predominância de casos de ISC-IS e ISC-OC(47).

Nesse mesmo sentido, ECR controlado avaliando se o uso de CHGL alcoólica era mais eficaz na prevenção da ISC que o uso de PVPI para a antissepsia da pele, imediatamente antes da incisão da pele na sala cirúrgica, entre 1.147 pacientes submetidos à cirurgia potencialmente contaminada, também identificou-se maior número de casos de ISC-IS, seguida por ISCIP(48).

No entanto, no presente estudo, diferindo da literatura, houve predominância da topografia de ISC-OC, seguida de ISC-IS equiparada com ISC-IP. 
Fernanda de Oliveira Andrade

Neste estudo não foi detectada diferença quanto à ocorrência de ISC entre a utilização de banho com solução de CHGL ou uso de TICHG.

Em relação ao uso de soluções antissépticas para o banho préoperatório, observa-se escassez de produção científica na área de enfermagem, não tendo sido localizado estudo semelhante ao presente na literatura nacional, havendo carência de investigações da mesma natureza, envolvendo cirurgias potencialmente contaminadas e uso de TICHG na literatura interncional.

O preparo pré-operatório da pele é considerado um processo importante para a prevenção ou redução da incidência de ISC. Existe uma grande variabilidade de escolha de soluções antissépticas, bem como das suas técnicas de aplicação( ${ }^{(49)}$.

Diretrizes internacionais ${ }^{(14,30)}$ citam que o uso de solução antisséptica contendo $\mathrm{CHG} 2 \%$ para o preparo pré-operatório da pele reduz a colonização da pele por microrganismos residentes e transitórios, o que pode colaborar para a redução do risco de ISC.

Embora existam limitações nas evidências científicas disponíveis, especialmente relacionadas à qualidade dos delineamentos de estudos conduzidos, os benefícios do preparo da pele, incluindo o banho, com soluções antissépticas, em especial a $\mathrm{CHG} 2 \%$, parece superar os potenciais danos ou riscos, uma vez que observa-se que, comparado ao não banho, ou banho com sabão comum, as investigações demonstraram menores taxas de ISC (34,54,55).

Entre os antissépticos recomendados para a antissepsia da pele, a CHG tem ampla utilização clínica atualmente, por ser um antisséptico de amplo espectro, com atividade contra bactérias Gram-positivas e Gram-negativas, vírus e fungos. Além disso, ela apresenta efeito residual de pelo menos cinco horas e não é inativada na presença de secreções e/ou sangue ${ }^{(32,49)}$.

Duas metanálises analisando diferenças em relação à ocorrência de ISC, segundo a utilização de banho com CHGL ou banho comum sem antisséptico, chegaram a conclusões diferentes ${ }^{(35,50)}$.

A primeira metanálise publicada incluiu 16 estudos, computando 17.932 pacientes submetidos a variados procedimentos cirúrgicos, e comparou o uso de CHG $4 \%$ convencional//íquida no banho pré-operatório com outros grupos 
Fernanda de Oliveira Andrade

(banho com água e sabão e nenhum banho), não tendo verificado redução significativa nas taxas de ISC. Os autores concluíram que não houve benefícios do uso de CHG 4\% convencional/líquida na prevenção da ISC, uma vez que não observaram redução significativa da ISC entre os grupos, embora considerem a prática de baixo risco e custo ${ }^{(50)}$.

Por outro lado, metanálise composta por quatro ECR, totalizando 8.787 pacientes submetidos a cirurgia de artroplastia de joelho, comparou a utilização de CHGL ao banho comum sem antisséptico e demonstrou uma incidência reduzida de infecção nos pacientes que utilizaram a CHGL para o preparo préoperatório da pele, correspondendo a uma redução de ISC de 1,69\%(35).

Reconhece-se que, para atingirem seu efeito antisséptico eficaz, é necessário que a $\mathrm{CHG}$, assim como outras soluções antissépticas, sejam aplicadas de forma uniforme, com duração e frequência de exposição padronizadas e de acordo com as instruções do fabricante ${ }^{(14,51)}$. Nota-se pela análise da literatura científica que, frequentemente, os estudos falham em padronizar de maneira rigorosa as técnicas de aplicação, o que pode favorecer a minimização da eficácia do produto nesses estudos.

Outro fator importante a ser destacado é que a concentração e as técnicas utilizadas para a aplicação da CHG na pele do paciente cirúrgico, bem como a ausência de um controle rigoroso e adequado durante a sua fabricação, conservação e manipulação, influenciam diretamente a eficácia da redução de microrganismos da pele, com consequente redução de sua eficácia na prevenção da ISC ${ }^{(49)}$.

Esse fator é consistente com o que já se sabe, ou seja, que a ação eficaz do agente antisséptico está vinculada a várias aplicações, em virtude de seu efeito cumulativo(14,30,52). Dessa forma, os produtos contendo $\mathrm{CHG}$ exigem, no mínimo, duas aplicações para obter o efeito antisséptico máximo; assim, geralmente são indicados banhos pré-operatórios repetidos para que as concentrações de CHG na pele atinjam sua concentração máxima, a fim de reduzir a microbiota cutânea ${ }^{(14,30)}$.

Entre as diversas formulações baseadas no produto, tem-se discutido a eficácia de sua aplicação por meio de TICHG, com estudos de metodologia e resultados bastante variáveis. 
Dessa forma, ECR controlado analisou pacientes submetidos a cirurgia de artroplastia articular total de extremidade inferior, comparando o uso de TICHG ao banho com água e sabão, ambos na noite anterior e na manhã da cirurgia, e observou menor taxa de infecção no grupo que utilizou o agente antisséptico, sendo semelhantes os fatores de risco avaliados entre os grupos $^{(53)}$.

Metanálise que analisou um ECR e cinco estudos de coorte retrospectivos, que incluíam ao todo 10.930 pacientes submetidos a artroplastia de joelho e quadril, comparando o uso de TICHG e o uso de CHGL, apontou taxas menores de ISC entre o grupo que utilizou $\mathrm{TICHG}^{(54)}$.

Estudo retrospectivo comparou a utilização de banho pré-operatório com TICHG ( $n=335)$, realizado com auxílio da equipe de enfermagem, imediatamente antes da transferência dos pacientes para a sala de cirurgia, à prática anteriormente implementada na instituição, ou seja, dois banhos préoperatórios com CHG 4\% convencional/líquida ( $n=284)$ antes da admissão hospitalar, sorteados aleatoriamente de um banco de dados. Os resultados demonstraram redução estatisticamente significante dos casos de ISC no grupo que utilizou as $\mathrm{TICHG}^{(34)}$.

Coorte retrospectiva acompanhando 3.717 pacientes submetidos à artroplastia total de joelho, em que 991 pacientes utilizaram 12 TICHG, sendo seis na noite anterior à cirurgia e os seis restantes na manhã da cirurgia, comparados a 2.726 pacientes que seguiram a rotina institucional (não descrita no estudo), identificou que o uso das TICHG na preparação da pele esteve associado ao risco reduzido de ISC(55).

Quanto à antissepsia intraoperatória da pele dos pacientes, ou seja, aquela realizada pelo cirurgião com o objetivo de reduzir os microrganismos presentes na pele, foi interessante observar que, neste estudo, empregou-se para antissepsia da pele do paciente a combinação de PVPI tópica seguida da utilização de PVPI degermante em grande parte dos sujeitos investigados. Cabe destacar que a compatibilidade da mistura de soluções PVPI e CHG alcoólica empregadas no preparo intraoperatório, no entanto, destaca-se que as taxas mais baixas de ISC estão relacionadas ao uso de CHG alcoólica sozinha ou combinada para a antissepsia da pele(52). 
Fernanda de Oliveira Andrade

Ensaio clínico controlado aleatório abrangendo 407 pacientes submetidos a cirurgia da coluna vertebral, analisando antissepsia da pele com PVPI seguida de CHG alcoólica, e outro grupo utilizando apenas PVPI, detectou, após análise microbiológica, que a antissepsia da pele com a aplicação de PVPI seguida de CHG alcoólica reduziu de forma mais eficaz a contaminação da ferida operatória ${ }^{(56)}$.

Coorte retrospectiva envolvendo 4.259 pacientes submetidos a histerectomias abdominais identificou que os pacientes que utilizaram a CHG alcoólica para antissepsia antes da incisão cirúrgica da pele desenvolveram menos casos de ISC do que os que utilizaram PVPI(57).

Cabe destacar a etiologia multifatorial da ISC, ou seja, a importância dos fatores considerados de risco para a ocorrência de ISC, e, para além das atividades relacionadas ao procedimento, também as variáveis relacionadas ao paciente $^{(10)}$.

Em relação às características clínicas e cirúrgicas dos pacientes incluídos, apesar de não serem detectadas diferenças estatísticas significativas entre os grupos, ou relação entre essas características e a ocorrência de ISC, foram observados, IMC $>30 \mathrm{~kg} / \mathrm{m}^{2}$ e escore ASA II e III.

Em relação ao sexo, alguns estudos de coorte, com pequeno número de sujeitos incluídos, apontam correlação entre a ocorrência de ISC e o sexo masculino entre pacientes submetidos a cirurgias colorretais ${ }^{(58,59)}$.

No entanto, esse aspecto permanece controverso, uma vez que a literatura é variável e estudos com maior número de sujeitos, como coorte composta por 2.618 pacientes submetidos a ileocolectomia, não encontraram diferença estatística significativa entre os $\operatorname{sexos}^{(60)}$. No presente estudo, a maioria da amostra foi constituída por pacientes do sexo feminino.

A idade superior a 50 anos, quando associada a outras comorbidades, é considerada fator de risco para a ocorrência de ISC $^{(61)}$. Contudo, os pacientes que participaram do presente estudo apresentaram idade entre 29 e 74 anos, com discreta diferença entre as médias dos pacientes que desenvolveram o diagnóstico de ISC (47,4 anos) em comparação com aqueles que não desenvolveram (44,4 anos). 
Fernanda de Oliveira Andrade

Dessa forma, investigação transversal prospectiva avaliando 93 pacientes submetidos a cirurgias ortopédicas limpas também observou que a média de idade dos pacientes que desenvolveram ISC foi de 47,3 anos e, dos pacientes que não desenvolveram, 42,2 anos ${ }^{(10)}$, não verificando correlação entre a idade e a ocorrência de ISC.

A média de IMC dos pacientes que desenvolveram o diagnóstico de ISC nos dois grupos refletiu obesidade. Sabe-se que a obesidade é considerada fator de risco independente para a ocorrência de ISC e outras complicações pós-operatórias, e vem sendo amplamente estudada pela literatura ${ }^{(62)}$.

Estudo de coorte retrospectivo constituído por 971 pacientes submetidas a cesariana comparou as taxas de ISC entre dois grupos: pacientes obesas e não obesas, e as taxas de ISC e complicações pós-operatórias foram mais prevalentes entre pacientes obesas ${ }^{(63)}$.

Coorte retrospectivo constituído por 132 pacientes submetidas a histerectomia total abdominal (HTA) comparou as taxas de ISC e as complicações pós-operatórias entre pacientes obesas (IMC $\left.<40 \mathrm{~kg} / \mathrm{m}^{2}\right)$ e pacientes com obesidade mórbida (IMC $\geq 40 \mathrm{~kg} / \mathrm{m}^{2}$ ); pacientes com obesidade mórbida apresentaram maior prevalência de ISC e de complicações pósoperatórias ${ }^{(64)}$.

No presente estudo, treze sujeitos apresentavam o diagnóstico de DM, destes, apenas três desenvolveram o diagnóstico de ISC entre os grupos. O controle glicêmico é essencial para a redução das taxas de ISC, sendo que a literatura demonstra que DM está associada de forma independente ao aumento da incidência de ISC ${ }^{(65)}$. Vale ressaltar os problemas referentes ao acompanhamento e registro da glicemia capilar identificados entre a amostra estudada.

Em estudo de coorte retrospectivo que avaliou as taxas de ISC em 495 pacientes portadores de $\mathrm{DM}$ e pacientes não diabéticos submetidos a laringectomia total, as taxas de ISC foram superiores no grupo de pacientes com DM $(10,9 \%)$ em comparação com as taxas de ISC nos pacientes não diabéticos $(4,7 \%)^{(66)}$.

A tricotomia é considerada fator de risco para a ISC, pois aumenta o risco de colonização da ferida operatória. Assim, quanto menor o tempo entre a 
Fernanda de Oliveira Andrade

realização da tricotomia e o ato cirúrgico, menor o risco de colonização da ferida operatória e eventual infecção. Nesse sentido, estudo retrospectivo analisou 700 prontuários de pacientes submetidos a cirurgias limpas, dos quais 189 (27\%) foram submetidos a tricotomia com lâmina de barbear e desenvolveram ISC ${ }^{(67)}$.

No presente estudo, mais da metade dos pacientes nos dois grupos realizaram a tricotomia de forma inadequada, com destaque para o uso de lâminas de barbear e cera depilatória quente, com o procedimento sendo realizado predominantemente no domicílio.

O escore ASA reflete as condições clínicas dos pacientes e é considerado fator de risco para o desenvolvimento de ISC. Quanto maior a classificação, maior o risco ${ }^{(68)}$, como o ocorrido entre os pacientes incluídos neste estudo, com predominância de escores de ASA II e III.

No presente estudo, os pacientes foram submetidos a procedimentos anestésico-cirúrgicos variados, com duração de aproximadamente duas horas e quarenta minutos.

A duração da cirurgia é um fator de risco para a ISC, pois permite que o potencial de contaminação por microrganismos aumente com o tempo de exposição da incisão aberta. Paralelamente, a contaminação das mãos do cirurgião aumenta significativamente, enquanto a concentração dos antibióticos profiláticos diminui(69).

Se administrado corretamente, o uso de antibiótico profilático reduz consideravelmente as taxas de ISC. Diretrizes da $\mathrm{WHO}^{(18)}$ recomendam a administração de antibioticoprofilaxia no período de até 120 minutos antes da incisão cirúrgica; já o Bérrios-Torres et al. ${ }^{(17)}$ recomenda o uso de antibiótico profilático, sem indicar, no entanto, o tempo específico para a administração no pré-operatório. A recomendação é administrar pouco antes da incisão cirúrgica da pele.

A hipotermia (temperatura $<36^{\circ} \mathrm{C}$ ) é uma complicação frequente e evitável, com várias consequências adversas. Em comparação com pacientes normotérmicos, pacientes com hipotermia são mais suscetíveis ao desenvolvimento de ISC(19). 
Fernanda de Oliveira Andrade

Foram detectadas, no presente estudo, falhas relacionadas ao registro e mensuração da temperatura corporal dos pacientes. No entanto, verificou-se hipotermia no POI, sendo a média de temperatura axilar, para os dois grupos, de $35,6^{\circ} \mathrm{C}$.

O tempo de hospitalização pré e pós-operatório, bem como, muitas vezes, a necessidade de reabordagem e reinternação hospitalar, aumentam a morbidade e mortalidade, com consequente prejuízo e aumento nos custos dos cuidados de saúde com os pacientes ${ }^{(70)}$.

Todavia, no presente estudo, nota-se que não houve diferença estatística significativa entre a média de hospitalização pré-operatória e pósoperatória entre os pacientes que desenvolveram o diagnóstico de ISC.

A falta de registros médicos e de enfermagem adequados também dificulta o processo de vigilância das ISC, tanto em âmbito hospitalar como durante a vigilância pós-alta. Muitas vezes, os sinais e sintomas relatados ou visualizados durante a visita pós-operatória ou retorno ambulatorial são subnotificados: dos sete casos de ISC no estudo, apenas um estava descrito no prontuário médico como ISC. Os demais foram identificados baseados em dados coletados por meio de vigilância ativa e passiva, submetidos a avaliação do Comitê de Adjudicação com experiência na área de controle e prevenção de IRAS.

Houve limitações no decorrer do estudo, dentre as quais a dificuldade financeira vivenciada pelos hospitais públicos, que afetou diretamente a instituição de saúde onde o estudo estava sendo realizado. Muitas cirurgias foram canceladas por motivos diversos, como falta de material e ausência do profissional médico para a realização do procedimento, o que impactou na seleção de um maior número de sujeitos participantes. Ademais, pacientes que utilizaram os produtos de forma inadequada precisaram ser excluídos do estudo. Cabe destacar, também, o alto índice de pacientes que faziam uso de antissépticos em sua rotina diária, o que também constituiu critério de exclusão. 
6 Conclusão 


\section{CONCLUSÃO}

Não houve diferença estatística significativa entre 0 uso de toalhas impregnadas com $\mathrm{CHG} 2 \%$ e o banho tradicional com $\mathrm{CHG} 2 \%$ convencional/líquida quanto à prevenção de ISC. A quantidade de casos de ISC identificados entre os GC e GI foram quantitativamente equivalentes, mas qualitativamente diferentes, segundo topografia de acometimento.

Os pacientes referiram maior quantidade de vantagens relativas à utilização das toalhas impregnadas com CHG $2 \%$; no entanto, as desvantagens citadas foram as mesmas entre os dois grupos. O custo de aquisição das toalhas impregnadas com $\mathrm{CHG} 2 \%$ é superior ao da $\mathrm{CHG}$ convencional/líquida, o que pode ser um impeditivo para sua implementação em muitas instituições hospitalares brasileiras.

A literatura científica sobre a temática é restrita e a qualidade das evidências é variada. Dessa maneira, torna-se necessário o investimento na condução de mais ensaios clínicos randomizados controlados, com maior número de sujeitos e protocolos cuidadosamente padronizados e detalhados, para a aplicação efetiva da $\mathrm{CHG} 2 \%$ na pele, a fim de que se possa demonstrar sua eficácia ou não, na prevenção ou redução da incidência da ISC.

Considerando-se que o preparo pré-operatório da pele com solução antisséptica é utilizado para reduzir ou eliminar microrganismos presentes na pele, com pequena ou nenhuma interferência em outros processos ou riscos para os pacientes, acredita-se que esta seja uma alternativa importante a ser explorada pela equipe de saúde entre as medidas de prevenção e controle de ISC. 
7 Referências 


\section{REFERÊNCIAS}

1. Brasil. Ministério da Saúde, Portaria GM n. 2.616, de 12 de maio de 1998. Institui a implantação do Programa de Controle de Infecção Hospitalares no âmbito estadual, municipal e nos serviços de saúde. In: Brasil. Ministério da Saúde. Programa de Controle de Infecção Hospitalares. Brasília; 1998.

2. Siegel JD, Rhinehart E, Jackson M, Chiarello L. Guideline for isolation precautions: preventing transmission of infectious agents in healthcare settings. HICPAC. 2007. Atlanta; 2007.

3. Brasil. Ministério da Saúde, Agência Nacional de Vigilância Sanitária, Gerência de Vigilância e Monitoramento em Serviços de Saúde, Gerência Geral de Tecnologia em Serviços de Saúde. Medidas de Prevenção de Infecção Relacionada à Assistência à Saúde. Brasília; 2017.

4. Roscani ANCP, Ferraz EM, Filho AGO, Freitas MIP. Validação de checklist para prevenção de infecção de sítio cirúrgico. Acta Paul Enferm. 2015; 28(6);553-65.

5. Brasil. Ministério da Saúde, Agência Nacional de Vigilância Sanitária, Gerência de Vigilância e Monitoramento em Serviços de Saúde, Gerência Geral de Tecnologia em Serviços de Saúde. Critérios Diagnósticos de Infecções Relacionadas à Assistência à Saúde. Brasília; 2017.

6. Aguiar APL, Prado PR, Opitz SP, Vasconcelos SP, Faro ARMC. Fatores associados à infecção de sítio cirúrgico em um hospital na Amazônia ocidental brasileira. Rev Sobecc. 2012;17(3):60-70.

7. Centers for Disease Control and Prevention. Surgical Site Infection (SSI) Event. Atlanta; 2017.

8. Leaper D, Ousey K. Evidence update on prevention of surgical site infection. Curr Opin Infect Dis. 2015;28(2):158-63.

9. Anderson DJ, Podgorny K, Berrios-Torres SI, Bratzler DW, Dellinger P, Greene L, Nyquist AC, Saiman L, Yokoe DS, Maragakis LL, Kaye KS. Strategies to prevent surgical site infections in acute care hospitals: 2014 update. Infection Control and Hospital Epidemiology. 2014;(35)2:67-88.

10. Ribeiro JC, Santos CB, Bellusse GC, Rezende VF, Galvão CM. Ocorrência e fatores de risco para infecção de sítio cirúrgico em cirurgias ortopédicas. Acta Paul Enferm. 2013;26(4):353-9. 
Fernanda de Oliveira Andrade

11. Pereira BRR, Mendonza IYQ, Couto BRGM, Ercole FF, Goveia VG. Artroplastia do quadril: prevenção de infecção do sítio cirúrgico. Rev Sobecc. 2014;19(4):181-7.

12. Ikeanyi UOE, Chukwuka CN, Chukwuanukwu TOG. Risk factors for surgical site infections following clean orthopaedic operations. Niger $\mathrm{J}$ Clin Pract. 2013;16(4):443-7.

13. Hechenbleikner EM, Wick EC. Surgical Readmissions: a method to the madness. JAMA Surg. 2014; 149(4):354-5.

14. Association for Professionals in Infection Control and Epidemiolology (APIC). Implementation Guide: Infection Preventionist's Guide to the OR. Arlington: 2018.

15. White A, Schneider T. Improving compliance whith prophylactic antibiotic. AORN J. 2007;85(1):173-80.

16. Salkind AL, Rao KC. Antibiotic prophylaxis to prevent surgical site infections. American Family Physician. 2011;83(5):585-9.

17. Berríos-Torres SI, Umscheid CA, Bratzler DW, Leas B, Stone EC, Kelz RR, et al. Centers for Disease Control and Prevention Guideline for the Prevention of Surgical Site Infection, 2017. Jama Surg. 2017; 152(8):784-91.

18. World Health Organization (WHO). Global Guidelines for the Prevention of Surgical Site Infection. Switzerland; 2016.

19. Mattia AL, Barbosa MH, Rocha AM, Pereira NHC. Hipotermia em pacientes na recuperação pós-anestésica: análise da intervenção de infusão venosa aquecida. Rev Eletr Enf [Internet]. 2014 [cited 2016 Out 22]; 16(4):787-94. Available from: http://dx.doi.org/10.5216/ree.v16i4.24222. Acesso em: 22 out. 2016.

20. Silva $A B$, Peniche ACG. Hipotermia perioperatória e aumento de infecção da ferida cirúrgica: estudo bibliográfico. Einstein. 2014;12(4):13-7.

21. Association of Perioperative Registered Nurses (AORN). Guideline for the Prevention of Unplanned Patient Hypothermia. Boston: 2016.

22. Eiselt D. Presurgical skin preparation with a novel $2 \%$ chlorhexidine gluconate cloth reduces rates of surgical site infection in ortthopaedic surgical patients. Orthop Nurs. 2009;28(3):141-5. 
Fernanda de Oliveira Andrade

23. Rodrigues AL, Simões MLPB. Incidência de infecção do sítio cirúrgico com o preparo pré-operatório utilizando iodopolividona $10 \%$ hidroalcoólica e clorexidina alcoolica 0,5\%. Rev Col Bras Cir. 2013;40(6):443-8.

24. Cunha BM, Oliveira SB, Santos-Neto L. Incidência de infecções em artroplastias de quadril e joelho em pacientes com artrite reumatoide e osteoartrite. Rev Bras Reumatol. 2011;51(6):603-15.

25. Gebrim CFL. Indicadores de processo para a prevenção da infecção do sítio cirúrgico em um hospital universitário do centro-oeste brasileiro [dissertação]. Goiânia: Faculdade de Enfermagem, Universidade Federal de Goiás;2013.

26. Hadiati DR, Hakimi M, Nurdiati DS. Skin preparation for preventing infection following caesarean (review). Cochrane Library [Internet]. 2014 [cited 2016 Set 29]:1-27. Available from: http://onlinelibrary. wiley.com/doi/10.1002/14651858.CD007462.pub3/full\#pdfsection. DOI: $10.1002 / 14651858$.

27. Kapadia BH, Issa K, McElroy MJ, Pivec R, verley JA, Mont MA. Advance pre-operative chlorhexidine preparation reduces periprosthetic infection following total joint arthroplasty. Semin Arthroplasty. 2013;(24):83-6.

28. Association of Perioperative Registered Nurses (AORN). Guideline for Preoperative Practice. Boston: 2017.

29. Sena AC, Nascimento ERP, Maia ARCR. Prática do enfermeiro no cuidado ao paciente no pré-operatório imediato de cirurgia eletiva. Rev Gaucha Enferm. 2013;34 (3):132-37.

30. Institute for Healthcare Improvement (IHI). How-to Guide: Prevent Surgical Site Infection for Hip and Knee Arthroplasty. Cambridge: 2012.

31. Brasil. Ministério da Saúde, Agência Nacional de Vigilância Sanitária. Higienização das Mãos em Serviços de Saúde. Brasília; 2007.

32. Damato JRG. Avaliação da eficácia antimicrobiana de sabonetes contendo: óleo essencial de melaleuca alternifolia versus triclosan versus clorexidina e o impacto na adesão à higienização das mãos pelo efeito aromaterápico [tese]. São Paulo: Escola de Enfermagem, Universidade de São Paulo;2015.

33. Webster J, Osborne S. Preoperative bathing or showering with skin antiseptics to prevent surgical site infection. Cochrane Library [Internet]. 2015 [cited 2016 Set 29]:1-49. Available from: http://www.cochrane.org/CD004985/WOUNDS preoperative-bathing-or- 
showering-with-skin-antiseptics-to-prevent-surgical-site-infection.

DOI: 10.1002/14651858.

34. Graling PR, Vasaly FW. Effectiveness of $2 \%$ CHG cloth bathing for reducing surgical site infections. AORN J. 2013;97(5):541-51.

35. Wang Z. Preoperative bathing with chlorhexidine reduces the incidence of surgical site infections after total knee arthroplasty. Medicine. 2017; 96(47):1-7.

36. Cowperthwaite L, Holm RL. Guideline implementation: preoperative patient skin antisepsis. AORN J. 2015;101(1);72-7.

37. Christóforo BEB, Carvalho DS. Cuidados de enfermagem realizados ao paciente cirúrgico no período pré-operatóriver. Rev Esc Enferm USP. 2009;43(1):14-22.

38. Kapadia BH, Zhou PL, Jauregui JJ, Mont MA. Does preadmission cutaneous chlorhexidine preparation reduce surgical site infections after total knee arthroplasty?. Clin Orthop Relat Res. 2016;474(7):1592-8.

39. Standard Protocol Items: Recommendations for Interventional Trials (SPIRIT) [Internet]. 2013. Disponível em: http://www.spirit-statement.org/wpcontent/uploads/2013/01/SPIRIT-Checklist-download-8Jan13.pdf. Acesso em: 10 fev. 2018.

40. Araújo JF, Valois EM, Cruz MCFN. Desenhos de estudos epidemiológicos boca-dividida e paralelo: uma revisão da literatura. Rev Bras Odontol. 2016; 73(1):60-3.

41. Polit DF, Beck CT, Hungler BP. Fundamentos de pesquisa em enfermagem. 7ª̣ed. Porto Alegre: Artmed; 2011.

42. Lima DVM. Desenhs de pesquisa: uma contribuição para autores. Online Braz J Nurs (Online). 2011; 10(2). Disponível em: https://www.objnursing.uff.br/index.php/nursing/article/viewFile/3648/pdf. Acesso em: 10 fev. 2018.

43. Oliveira MAP, Parente RCM. Entendendo ensaios clínicos randomizados. Bras J Video-Sur. 2010;3(4):176-180

44. Oliveira RA. Fatores de risco para infecção do sítio cirúrgico em transplante de fígado: coorte histórica [dissertação]. São Paulo: Escola de Enfermagem, Universidade de São Paulo; 2016. 
Fernanda de Oliveira Andrade

45. Guatura GMGBS. Vigilância Pós Alta em Infecção de Sitio Cirurgico: Criação e Validação de um instrumento [dissertação]. São Paulo: Escola de Enfermagem, Universidade de São Paulo; 2017.

46. Brasil. Conselho Nacional de Saúde, Resolução n. 466, de 12 de dezembro de 2012. Institui as diretrizes e normas regulamentadoras de pesquisas envolvendo seres humanos. In: Brasil. Conselho Nacional de Saúde. Brasília; 2012.

47. Feitosa RGF, Fernandes FAM, Júnior ONA, Costa FA, Cavalcante LD. Análise da incidência de infecção de sítio cirúrgico em cirurgias oncológicas do aparelho digestivo no Hospital Geral de Fortaleza. Medicina (Ribeirão Preto). 2014; 47(2);157-64.

48. Tuuli MG, Liu J, Stout MJ, Martin S, Cahill AG, Odibo AO, et al. A Randomized Trial Comparing Skin Antiseptic Agents at Cesarean Delivery. N Engl J Med .2016; 374(7); 647-55.

49. Quirós R, Carneiro M, Luquerna XC, Díaz MAC, Lopes $P$, Hawkins CM. Recomendações para o preparo pré-operatório da pele para prevenção de infecções no sítio cirúrgico. J Infect Control 2017;6(3);73-90.

50. Chlebicki MP, Safdar N, O’Horo JC, Maki DG. Preoperative chlorhexidine shower or bath for prevention of surgical site infection: a meta-analysis. Am J Infect Control. 2013;(41):167-73.

51. Edmiston CE, Krepel CJ, Spencer MP, Ferraz AA, Seabrook GR, Lee CJ, et al. Preadmission Application of 2\% Chlorhexidine Gluconate (CHG): Enhancing Patient Compliance While Maximizing Skin Surface Concentrations. Infection Control \& Hospital Epidemiology. 2016; 37(3); 254-9.

52. Dumville JC, McFarlane E, Edwards P, Lipp A, Holmes A, Liu Z. Preoperative skin antisseptics for preventing surgical wound infections after clean surgery (Review). Cochrane Library [Internet]. 2015 [cited 2017 Nov 29]:1-49.

Available from:http://cochranelibrarywiley.com/doi/10.1002/14651858.CD003949.pub3/pd f. DOI: 10.1002/14651858.CD003949.pub4.

53. Kapadia BH, Elmallah RK, Mont MA. A Randomized, Clinical Trial of Preadmission Chlorhexidine Skin Preparation for Lower Extremity Total Joint Arthroplasty. The Journal of Arthroplasty. 2016; 31; 2856-61.

54. Cai Y, Hou WH, Xu ZYP. Preoperative chlorhexidine reduces the incidence of surgical site infections in total knee and hip arthroplasty: A systematic review and meta-analysis. International Journal of Surgery. 2017; 39; $221-8$. 
Fernanda de Oliveira Andrade

55. Kapadia BH, Zhou PL, jauregui JJ, Mont MA. Does Preadmission Cutaneous Chlorhexidine Preparation Reduce Surgical Site Infections After Total Knee Arthroplasty?. Clin Orthop Relat Res. 2016; 474; 1592-8.

56. Sanger PC, Ramshorst GHV, Mercan E, Huang S, Hartzler A, Armstrong CAL, et al. Prognostic Model of Surgical Site Infection Using Daily Clinical Wound Assessment. J Am Coll Surg.2016;223(2);259-70.e2. DOI: 10.1016/j.jamcollsurg.2016.04.046.

57. Uppal S, Harris J, Al-Niaimi A, Swenson CW, Pearlman MD, Reynolds RK et al. Prophylactic Antibiotic Choice and Risk of Surgical Site Infection After Hysterectomy. Obstet Gynecol. 2016; 127(2); 321-9. DOI: $10.1097 /$ AOG.0000000000001245.

58. Gomila A, Carratala J, Biondo S, Badia JM, Fraccalvieri D, Shaw E, et al. Predictive factors for early- and late-onset surgical site infections in patients undergoing elective colorectal surgery. A multicentre, prospective, cohort study. Journal of Hospital Infection. 2018; xxx; 1-7.

59. Fusco SFB, Massarico NM, Alves MVMFF, Fortaleza CMCB, Pavan ECP, Palhares VC, et al. Infecção de sítio cirúrgico e seus fatores de risco em cirurgias de cólon. Rev Esc Enferm USP. 2016;50(1):43-9. DOI: http://dx.doi.org/10.1590/S0080-623420160000100006.

60. Loveday HP, WIson JA, Pratt RJ, Golsorkhi M, Tingle A, Bak A. J Hosp Infect. 2014;86 Suppl 1:S1-70. Epic3: national evidence-based guidelines for preventing healthcare-associated infections in NHS hospitals in England. DOI: 10.1016/S0195-6701(13)60012-2.

61. Santos GC, Baylão AFG, Borges SCF, Silva LA, Batista MHJ, Leite GR. Incidência e fatores de risco de infecção de sítio cirúrgico: revisão integrative. Rev Eletrônica Itinerarius Reflectionis. 2015; 11(1). DOI: 10.5216/rir.v11i1.34142.

62. George J, Piuzzi NS, Mitchell BA, Sodhi N, Khlopas AA, Mont MA. Association Between Body Mass Index and Thirty-Day Complications After Total Knee Arthroplasty. The Journal of Arthroplasty. 2018; 33; 865-71.

63. Vegel, AJ, Benden DM, Borgert AJ, Kallies KJ, Kothari SN. Impact of Obesity on Cesarean Delivery Outcomes. WMJ. 2017; 116(4); 206-9.

64. Alp E, Cevahir F, Ersoy S, Guney A. Incidence and economic burden of prosthetic joint infections in a university hospital: A report from a middle-income country. 2016; 9(4). DOI: https://doi.org/10.1016/j.jiph.2015.12.014. 
65. Tomioka K, Murakami M, Fujimori A, Watanabe M, Koizumi T, Goto S, et al. Risk Factors for Transumbilical Wound Complications in Laparoscopic Gastric and Colorectal Surgery. In vivo. 2017; 31; 943-8.

66. Filimonov A, Brady JS, Govindan A, Merchant A, Eloy JÁ, Baredes S, Park $\mathrm{RCW}$. Postoperative complications of total laryngectomy in diabetic patients. Laringoscope. 2017; 127(10). DOI: https://doi.org/10.1002/lary.26478.

67. Gebrim L, Melchiro CF, Amaral LMRM, Barreto NS, Palos RASP, Aparecida M. Tricotomia pré-operatória: aspectos relacionados à segurança do paciente. Rev. Eletrônica. Enferm. 2014; $34 . \quad$ Disponível: http://scielo.isciii.es/pdf/eg/v13n34/pt_administracion3.pdf. Acesso: 21 jul.17.

68. Ercole FF, Franco LMC, Macieira TGR, Wenceslau LCC, Resende HIN, Chianca TCM. Risco para infecção de sítio cirúrgico em pacientes submetidos a cirurgias ortopédicas. Rev. Latino-Am. Enfermagem. 2011; 19(6).

69. Pop-Vicas A, Musuuza JS, Schmitz M, Al-Niami A, Safdar N. Incidence and risk factors for surgical site infection posthysterectomy in a tertiary care center. American Journal of Infection Control. 2017; 45; 284-7.

70. Pierson RC, Scott NP, Briscoe KE, Haas DM. A review of post-caesarean infectious morbidity: how to prevent and treat. Journal of Obstetrics and Gynaecology. 2018; (online); DOI: 10.1080/01443615.2017.1394281. 
Apêndices 


\section{APÊNDICES}

APÊNDICE A - Instruções para o uso das toalhas impregnadas com CHG $2 \%$

Prezado Sr(a):

A infecção de sítio cirúrgico é a terceira infecção mais frequente adquirida no hospital. A utilização de antissépticos para o preparo préoperatório da pele está indicada pela literatura, pois remove e/ou reduz a contagem de microrganismos da pele e pode contribuir para a redução das taxas de infecção.

O $\operatorname{Sr}(a)$ está recebendo doze toalhas contendo gluconato de clorexidina $2 \%$ cada, um potente antisséptico que proporciona uma proteção prolongada e eficaz, a ser utilizado no banho pré-operatório.

\section{Orientacões:}

- Utilizar seis toalhas na noite anterior à cirurgia (entre 20 e 22h) e as seis restantes na manhã da cirurgia (entre 5 e 6h);

- Não é necessário tomar banho antes da aplicação das toalhas com CHG $2 \%$. Caso tome banho, esperar no mínimo duas horas antes de utilizar as toalhas;

- Não tomar banho entre ou após a utilização das toalhas;

- Não utilizar bucha de banho ou qualquer outro item para esfregar o produto no corpo;

- Não aplicar qualquer substância na pele, como cremes, óleos, hidratantes, maquiagem, antes, entre ou após o uso das toalhas com CHG $2 \%$;

- Não utilizar o produto no rosto, cabelo e região íntima;

- Estar com o cabelo seco para realização da cirurgia; 
Fernanda de Oliveira Andrade

- Aplicar as toalhas de forma que o produto seja distribuído de forma igual e em sentido único em todas as partes do corpo (exceto rosto, cabelo e região íntima);

- Após o uso das toalhas com CHG 2\%, esperar o produto secar na pele, não utilizar toalhas para se secar e vestir roupas limpas.

\section{Modo de utlizacão:}

\section{Lavar as mãos;}

Retirar a roupa;

Utilizar uma toalha para cada sítio descrito abaixo:

1 Pescoço (queixo), Tórax e Abdome - frente: iniciar no queixo, descendo até a região suprapúbica. Não voltar e não esfregar a toalha na pele. Após limpar toda a região, descartar a toalha.

2 Braço Direito - frente e atrás: iniciar pelo ombro, descendo para as mãos (inclusive entre os dedos), e por último higienizar a axila. Não voltar e não esfregar a toalha na pele. Após limpar todo o membro, descartar a toalha.

3 Braço Esquerdo - frente e atrás: iniciar pelo ombro, descendo para as mãos (inclusive entre os dedos), e por último higienizar a axila. Não voltar e não esfregar a toalha na pele. Após limpar todo o membro, descartar a toalha.

4ํ Pescoço (nuca), Tórax - atrás: iniciar na nuca, descendo até os glúteos (exceto região íntima). Não voltar e não esfregar a toalha na pele. Após limpar toda a região, descartar a toalha.

5o Perna D - frente e atrás: iniciar pela região inguinal (incluindo a virilha), descendo para a perna e o pé (inclusive entre os dedos). Não voltar e não esfregar a toalha na pele. Após limpar todo o membro, descartar a toalha.

60 Perna E - frente e atrás: iniciar pela região inguinal (incluindo a virilha), descendo para a perna e o pé (inclusive entre os dedos). Não voltar e não esfregar a toalha na pele. Após limpar todo o membro, descartar a toalha. 


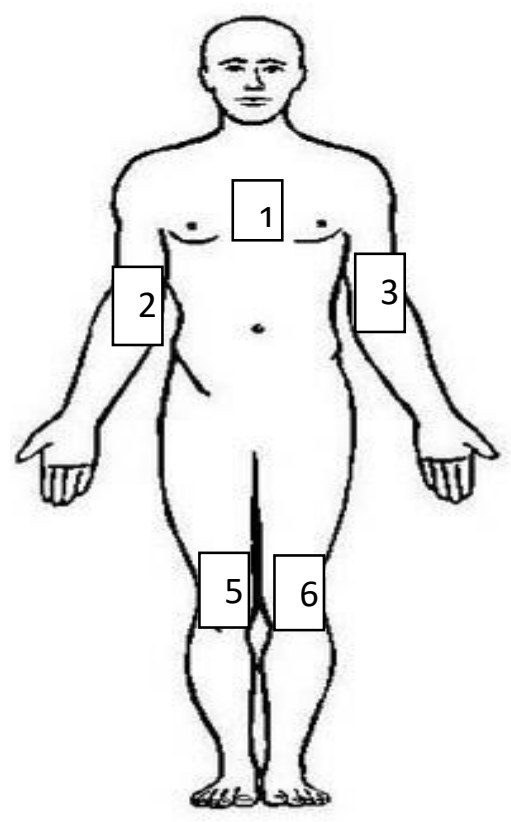

FRENTE

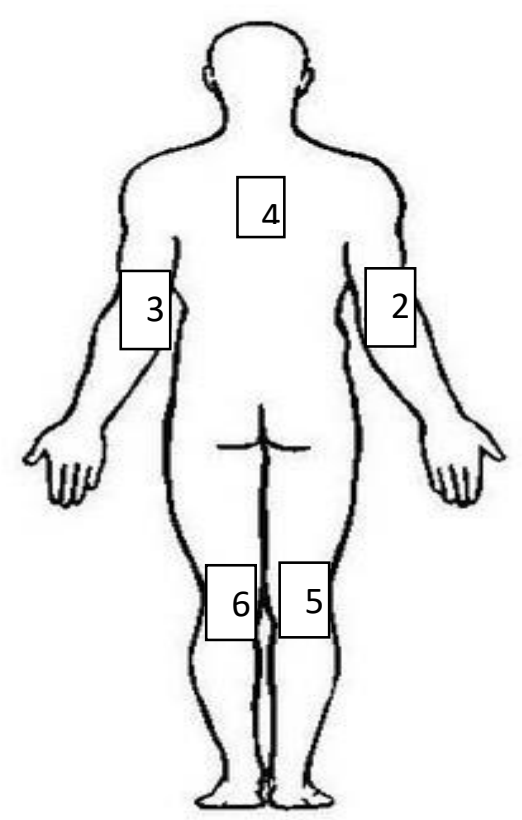

ATRÁS 
Fernanda de Oliveira Andrade

APÊNDICE B - Instruções para o uso da CHG $2 \%$ convencional/líquida

Prezado Sr (a):

A infecção de sítio cirúrgico é a terceira infecção mais frequente adquirida no hospital. A utilização de antissépticos para o preparo préoperatório da pele está indicada pela literatura, pois remove e/ou reduz a contagem de microrganismo da pele e pode contribuir para redução das taxas de infecção.

O Sr(a) está recebendo dois frascos contendo gluconato de clorexidina $2 \%$ (líquida) cada, um potente antisséptico que proporciona uma proteção prolongada e efetiva, a ser utilizado no banho pré-operatório.

\section{Orientacões}

- Utilizar um frasco na noite anterior à cirurgia (entre 20 e 22h) e o outro frasco na manhã da cirurgia (entre 6 e 8h);

- Não utilizar bucha de banho ou qualquer outro item para esfregar o produto no corpo;

- Não utilizar outros produtos durante o banho (sabonete comum, sabão, etc.);

- Não aplicar qualquer substância na pele, como cremes, óleos, hidratantes, antes, entre ou após o banho com CHG $2 \%$ convencional/líquida;

- Não utilizar o produto no rosto, cabelo e região íntima;

- Estar com o cabelo seco para realização da cirurgia.

\section{Modo de utilizacão}

- Espalhar o produto na pele durante o banho e massagear por 3 minutos, de forma que seja distribuído igualmente em todas as partes do corpo (exceto no rosto, cabelo e região íntima). Depois, enxaguar com água e se secar com uma toalha limpa e seca, e vestir roupas limpas.

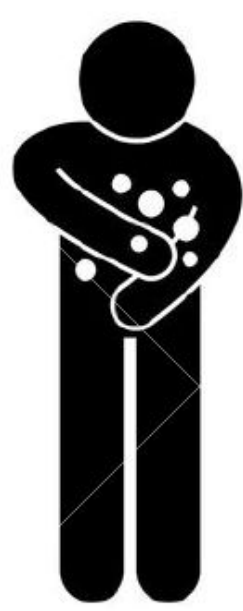


Fernanda de Oliveira Andrade

APÊNDICE C - Instrumento de coleta de dados

Data da Coleta:

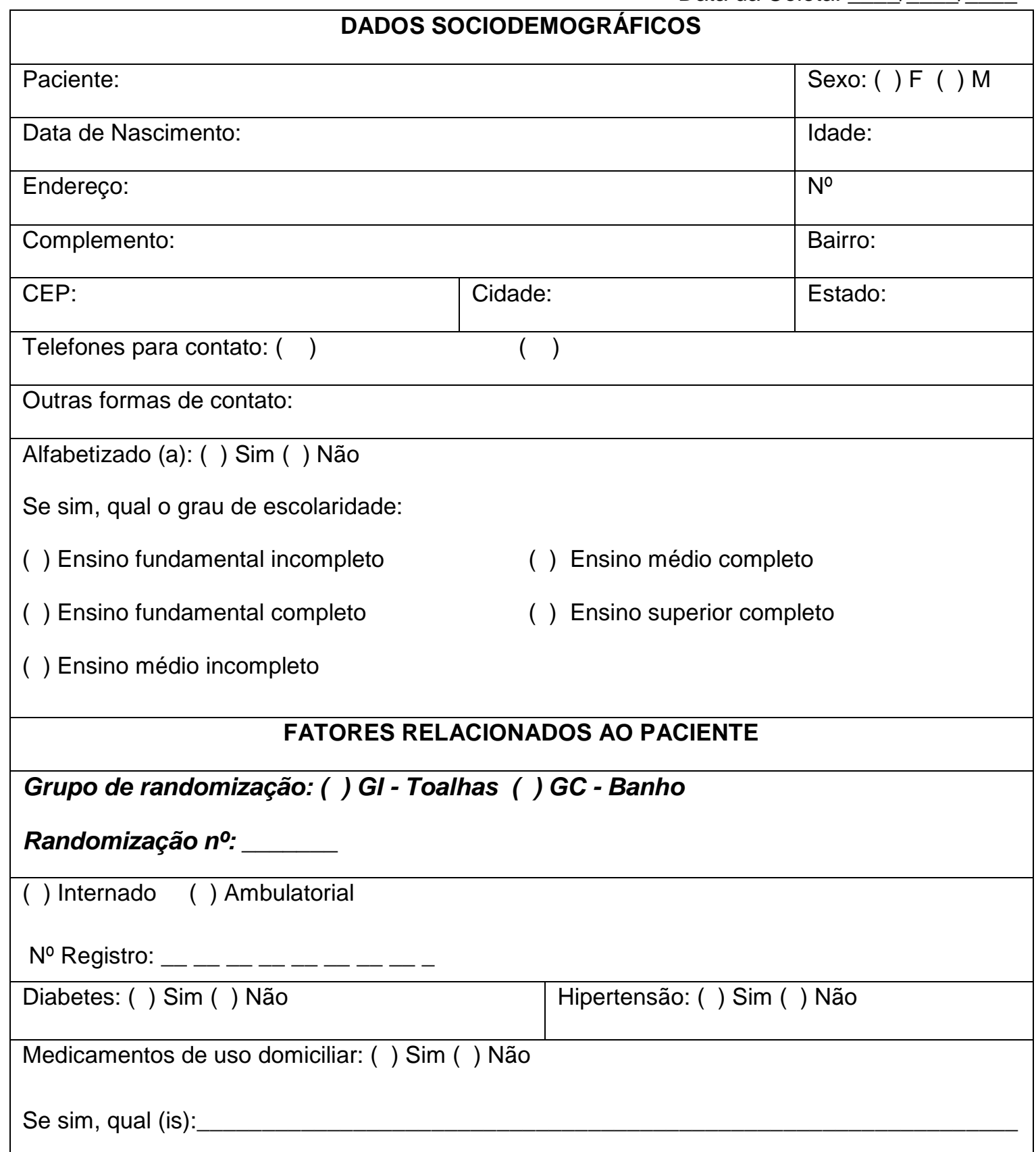


Fernanda de Oliveira Andrade

Neoplasia: ( ) Sim ( ) Não

Se sim, em tratamento com:

( ) Quimioterapia

( ) Radioterapia

( ) Outros:

Drogas imunossupressoras: ( ) Sim ( ) Não

( ) Prednisona

( ) Hidrocortisona

( ) Micofenolato de mofetila

( ) Ciclosporina

( ) Tacrolimo (Prograf)

( ) Micofenolato (Mifortyc)

( ) Metilprednisolona (Solu-medrol)

( ) Outros:

Peso: $\quad$ Altura: $\quad$ IMC:

Estado nutricional: ( ) Adequado ( ) Inadequado ( ) Obesidade

Etilista: ( ) Sim ( ) Não ( ) Ex-Etilista

Se sim, frequência de uso da bebida alcoólica:
( ) 1 vez/semana
( ) 4 vezes/semana
( ) Diariamente
( ) 2 vezes/semana
( ) 5 vezes/semana
( ) 3 vezes/semana
( ) 6 vezes/semana

Se ex-etilista, há quanto tempo parou (expresso em dias/meses):

Tabagista: ( ) Sim ( ) Não ( ) Ex-Tabagista

Se sim, tempo de uso do tabaco (expresso em meses):

Se ex-tabagista, há quanto tempo parou (expresso em dias/meses): 
Fernanda de Oliveira Andrade

Cirurgias anteriores: ( ) Sim ( ) Não

Se sim:

Cirurgia

( ) $>30$ dias ()$<30$ dias

Implante de prótese ( ) Sim ( ) Não
( ) $>1$ ano
()$<1$ ano

Alergia conhecida a CHG 2\%: ( ) Sim

( ) Não

( ) Não sei

Uso habitual no banho de produtos que contenham antissépticos:

( ) Sim ( ) Não

Se sim, qual a frequência de utilização:
( ) 1 vez/semana
( ) 4 vezes/semana
( ) Diariamente
( ) 2 vezes/semana
( ) 5 vezes/semana
( ) 3 vezes/semana
( ) 6 vezes/semana

Em uso de antibiótico(s): ( ) Sim ( ) Não

Se não, informe a data de utilização pela última vez:

( ) $<7$ dias ()$>14$ dias

\section{FATORES RELACIONADOS AO PREPARO PRÉ-OPERATÓRIO}

Data da admissão hospitalar:

Horário da admissão hospitalar:

Diagnóstico médico pré-operatório:

Cirurgia proposta:

Data da cirurgia:

Horário agendado para a cirurgia:

Tempo de hospitalização pré-operatória, em dias:

Infecção em outro sítio: ( ) Sim ( ) Não

Sem sim, qual(is): 
Fernanda de Oliveira Andrade

Tricotomia: ( ) Sim ( ) Não

Se sim:

Data: Horário:

Instrumento utilizado: ( ) Tricotomizador elétrico ( ) Lâmina ( ) Outro:

Lesão devido ao procedimento: ( ) Sim ( ) Não ( ) Não se aplica

Se sim: ( ) superficial ( ) profunda

Preparo pré-operatório da pele: ( ) Sim ( ) Não

Produto utilizado: ( ) CHG 2\%-convencional/líquida ( ) Toalhas impregnadas com CHG 2\%

Todas as orientações para o uso da CHG 2\% (toalhas impregnadas) foram seguidas:

\section{( ) Sim ( ) Não}

( ) Utilizou seis toalhas na noite anterior à

( ) Não utilizou bucha de banho ou qualquer cirurgia (entre 20 e 22h) e as seis outro item para esfregar o produto no restante na manhã da cirurgia (entre $5 \mathrm{e}$ corpo

6h)

( ) Não aplicou qualquer substância na pele,

( ) Não tomou banho antes da aplicação das como cremes, óleos, hidratantes, toalhas com $\mathrm{CHG} 2 \%$; caso tenha tomado banho, não utilizou outros maquiagens, antes, entre ou após o uso produtos (sabonete comum, sabão, etc.) e esperou por no mínimo duas horas antes de aplicar as toalhas com CHG 2\% das toalhas impregnadas com CHG $2 \%$

( ) Não utilizou o produto no rosto, cabelo e região íntima

( ) Esta com o cabelo seco para realização da cirurgia

( ) Não tomou banho entre ou após a ( ) Não realizou o enxague do corpo após a utilização das toalhas utilização das toalhas com $\mathrm{CHG} 2 \%$

Todas as orientações para o uso da CHG 2\% (convencional/líquida) foram seguidas:

$$
\text { ( ) } \operatorname{Sim}(\text { ) Não }
$$

( ) Utilizou um frasco na noite anterior à

( ) Não utilizou bucha de banho ou qualquer cirurgia (entre 20 e $22 \mathrm{~h}$ ) e o outro frasco na manhã da cirurgia (entre 5 e $6 \mathrm{~h}$ ) outro item para aplicar o produto no corpo

( ) Espalhou o produto na pele durante o banho e massageou por 3 minutos

( ) Enxaguou com água, se secou com uma toalha limpa e seca, e vestiu roupas limpas

( ) Não tomou banho após ou entre o uso da CHG $2 \%$ convencional/líquida

( ) Não aplicou qualquer substância na pele, como cremes, óleos, hidratantes, maquiagens, antes, entre ou após o uso da CHG 2\% convencional/líquida

( ) Não utilizou o produto no rosto, cabelo e região íntima 
Fernanda de Oliveira Andrade

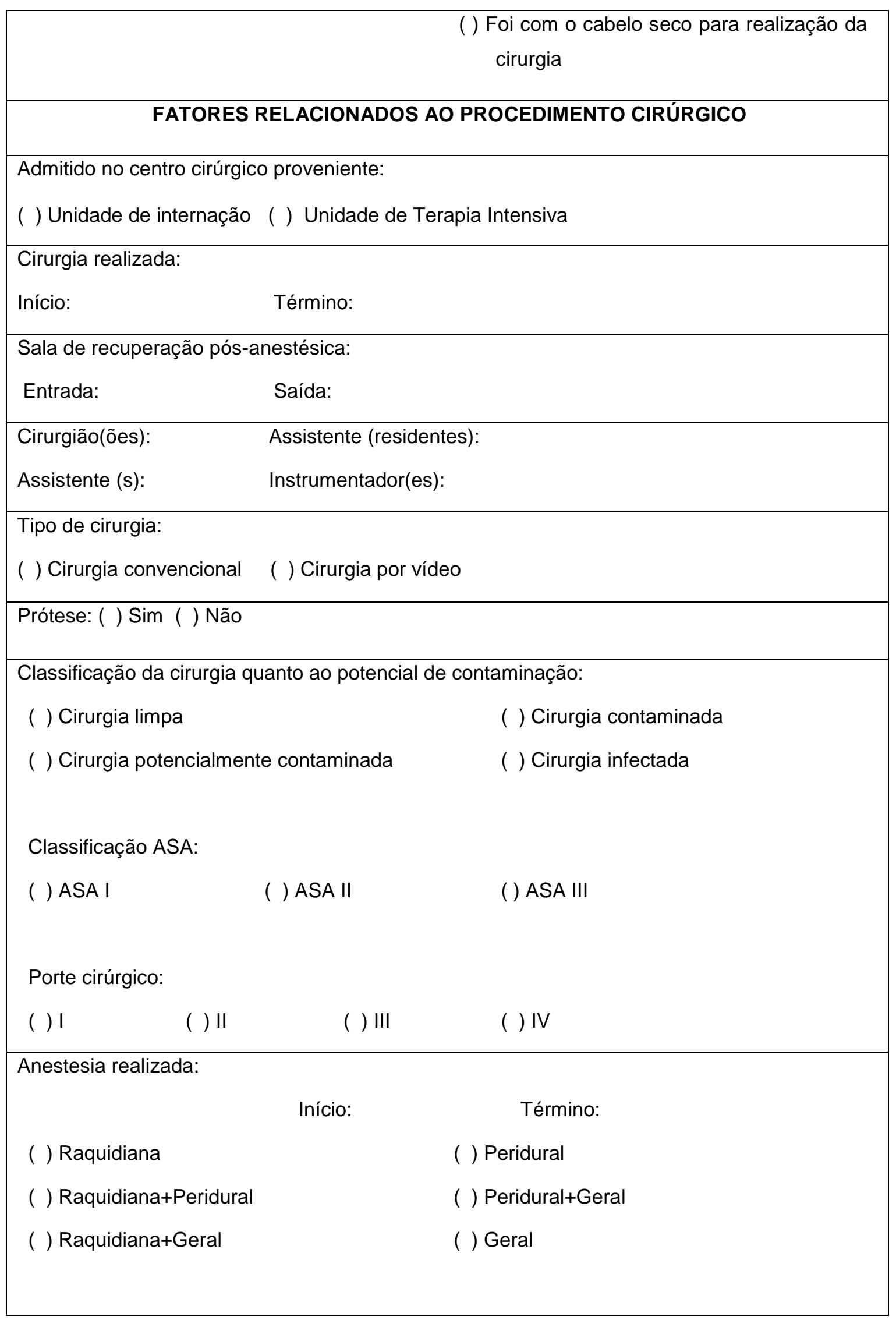


Fernanda de Oliveira Andrade

Antissepsia da pele na sala cirúrgica: ( ) Sim ( ) Não

Se sim:

( ) PVPI Tópico ( ) PVPI Degermante ( ) Clorexidina Alcoólica ( ) Clorexidina Degermante

( ) Outro:

Antibioticoprofilaxia: ( ) Sim ( ) Não

Se sim:

Antibiótico (s), dosagem e a via de administração prescrita:

Horário da administração da antibioticoprofilaxia antes da cirurgia:

( ) $>60 \min ()<60 \min$

Manutenção da antibioticoprofilaxia durante o procedimento cirúrgico:

( ) Sim ( ) Não

Valor glicêmico $(\mathrm{mg} / \mathrm{dl})$ :

Temperatura $\left({ }^{\circ} \mathrm{C}\right)$ :

Intercorrências no intraoperatório: ( ) Sim ( ) Não

Sem sim, qual(s):

Realizado hemotransfusão de concentrado de hemácias no intraoperatório: ( ) Sim ( ) Não Se sim:

Número de concentrado de hemácias (em unidades):

Momento de administração: ( ) Pré-operatório ( ) Intraoperatório ( ) Pós-operatório Uso de drogas vasopressoras? ( ) Sim ( ) Não

Dispositivos instalados no centro cirúrgico:

( ) Cateter venoso periférico

( ) Cateter venoso central - em veia jugular interna

( ) Cateter venoso central - em veia subclávia

( ) Cateter venoso central - em veia femoral

( ) Cateter venoso central - para hemodiálise

( ) Cateter de Swan-Ganz

( ) Sonda nasogástrica

( ) Cateter para monitorização de pressão arterial invasiva

( ) Cateter peridural

( ) Sonda vesical de demora

( ) Cateter de oxigênio

( ) Máscara de oxigênio

( ) Ventilação mecânica

( ) Outro(s): 
Fernanda de Oliveira Andrade

Drenos instalados no centro cirúrgico:

( ) Dreno de Penrose

( ) Dreno Suctor

( ) Outro(s):

FATORES RELACIONADOS AO PÓS-OPERATÓRIO IMEDIATO

Admissão: ( ) Unidade de internação ( ) Unidade de Terapia Intensiva

Data

Horário:

$\mathrm{h}: \quad \mathrm{m}$

Valor glicêmico:

Temperatura axilar:

Em uso de antibiótico(s): ( ) Sim ( ) Não

Se sim:

Antibiótico(s), dosagem prescrita e via de administração prescrita: 
Fernanda de Oliveira Andrade

Data do contato:

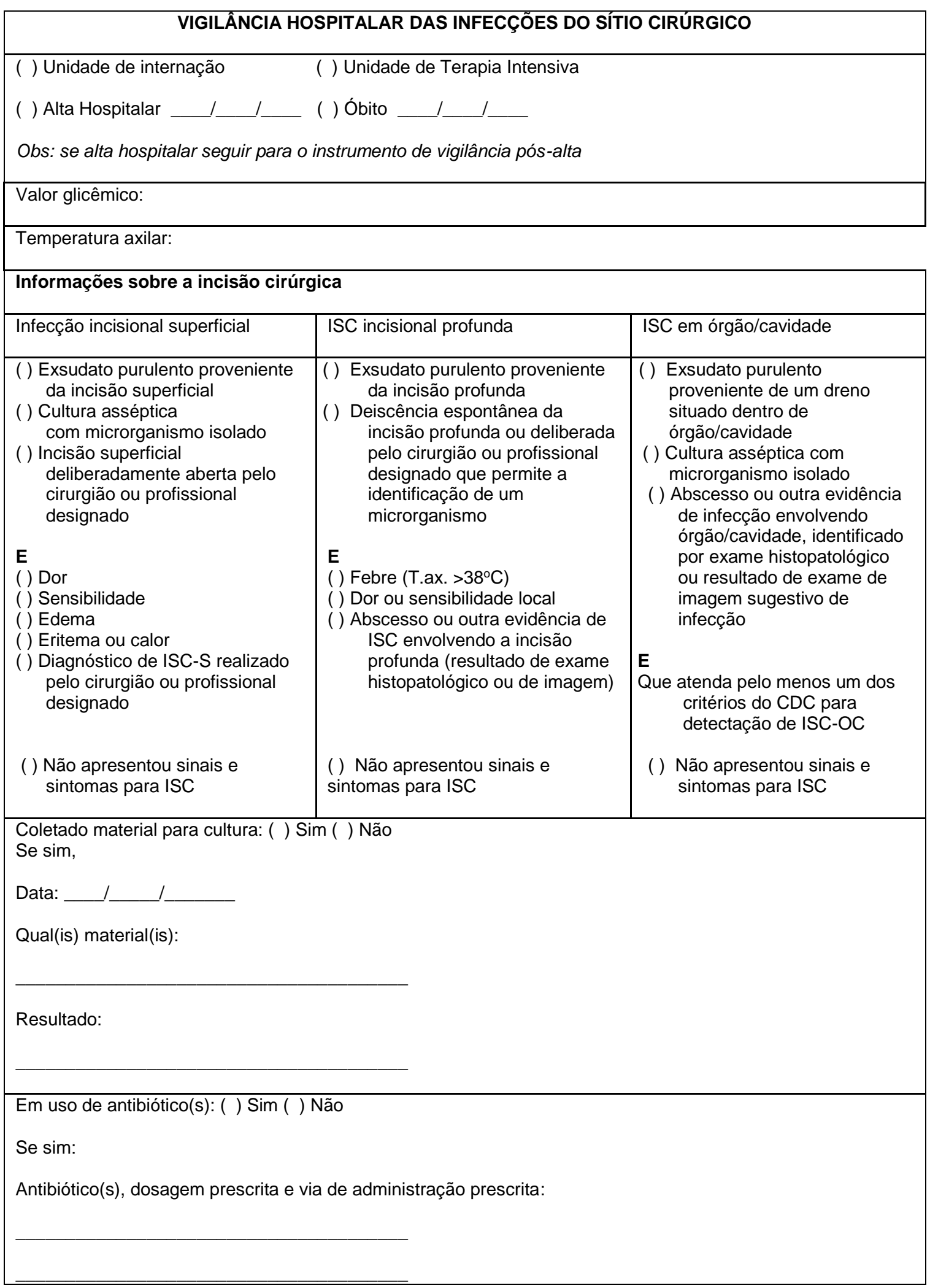


Fernanda de Oliveira Andrade

ISC: ( ) Sim ( ) Não

Se sim:

Classificação da ISC:

( ) ISC incisional superficial ( ) ISC incisional profunda ( ) ISC em órgão/cavidade

Houve registro de diagnóstico de ISC pelo profissional médico:

( ) $\operatorname{Sim}$ ( ) Não 


\section{APÊNDICE D - Termo de Consentimento Livre e Esclarecido}

Nós, pesquisadores da Escola de Enfermagem da Universidade de São Paulo, estamos convidando o(a) Sr(a) para participar de um estudo intitulado "Infecção do sítio cirúrgico e o uso de toalhas impregnadas com gluconato de clorexidina $2 \%$ no pré-operatório da pele: ensaio clínico randomizado - estudo piloto".

PESQUISADOR RESPONSÁVEL: Fernanda de Oliveira Andrade

CARGO/FUNÇÃO: Enfermeira

INSCRIÇÃO CONSELHO REGIONAL DE ENFERMAGEM № 326.548/PR

LOCAL: Hospital de Clínicas da Universidade Federal do Paraná

A clorexidina $2 \%$ é um potente antisséptico usado normalmente no hospital para eliminar bactérias causadoras de infecção da ferida operatória, e é essencial para promover melhores resultados na prevenção e controle de infecção. O objetivo deste estudo é determinar a eficácia das toalhas impregnadas com clorexidina $2 \%$ em comparação ao banho pré-operatório tradicional com clorexidina $2 \%$ convencional/líquida na prevenção ou redução da ocorrência de infecção do sítio cirúrgico entre pacientes submetidos a cirurgias eletivas potencialmente contaminadas.

A pesquisa será realizada no hospital, no período antes e após a cirurgia, e envolverá a realização de perguntas pelo pesquisador e registro destas informações em um formulário de coleta de dados. O pesquisador também o visitará durante sua internação e no retorno ambulatorial. Quando tiver alta hospitalar, o pesquisador realizará ligações telefônicas a partir do $30^{\circ}$ dias pós-cirurgia.

Para sua participação nesta pesquisa não haverá nenhum tipo de gasto financeiro ou necessidade de procedimento invasivo, como coleta de sangue ou exames radiológicos etc.

Para a realização desta investigação serão formados dois grupos: um que usará toalhas impregnadas com um produto (clorexidina $2 \%$ ), e outro grupo que utilizará apenas o produto em sua forma líquida (clorexidina $2 \%$ ) durante o banho pré-operatório. O grupo ao qual o(a) Sr(a) pertencerá será decidido por sorteio e, em nenhum dos grupos, o(a) Sr(a) estará prejudicado, pois o produto utilizado é o mesmo em qualquer dos grupos, mudando apenas a forma de aplicação do produto. A clorexidina é um produto seguro e já amplamente utilizado nos ambientes hospitalares, recomendado pelos órgãos governamentais brasileiros e mundiais. Além disso, também está presente em muitos produtos comprados em supermercados, como sabonetes, enxaguatórios bucais, entre outros. Dessa forma, é possível que o(a) $\operatorname{Sr}(a)$ já o tenha utilizado anteriormente.

Esta intervenção não oferece riscos à saúde, ou seja, não há prejuízo na execução e segurança da cirurgia, já que o mesmo faz parte das rotinas de muitos hospitais, inclusive no hospital onde o(a) $\operatorname{Sr}(a)$ está sendo atendido(a).

Como a pesquisa está utilizando um produto que já faz parte do dia a dia do hospital, a chance de desconfortos ou riscos é mínima, e, caso ocorram, podem ser de sensação de ressecamento ou algum tipo de irritação na pele, que passará após a suspensão da utilização do produto. Em caso de dúvidas ou de reações de qualquer natureza, o(a) Sr(a) deverá comunicar imediatamente ao pesquisador, que tomará as medidas necessárias, que podem envolver a suspensão imediata da utilização dos produtos e, caso necessário, encaminhamento para atendimento médico.

O benefício direto para o participante é a colaboração dos produtos testados na diminuição da chance de haver infecção na sua cirurgia. Embora outros fatores de risco possam contribuir para sua ocorrência, acredita-se que as medidas empregadas reduzirão sua chance. Além disso, a importância desse estudo é determinar as estratégias de prevenção ideais e, assim, melhorar os resultados de pacientes que precisem de tratamento semelhante.

$\mathrm{O}$ pesquisador garante manter o mais amplo e absoluto sigilo sobre sua identidade durante e após o término da pesquisa. O pesquisador tratará a sua identidade com padrões profissionais de sigilo. Seu nome ou o material que indique a sua participação não será utilizado sem a sua permissão. O(a) Sr(a) não será identificado(a) em nenhuma publicação que possa resultar deste estudo. A participação no estudo não acarretará custos para o(a) $\mathrm{Sr}(\mathrm{a})$ e, caso haja, com as devidas comprovações legais, o pesquisador acionará recursos próprios para a compensação financeira. Caso a pesquisa lhe cause algum dano explicitado nos riscos ou ocorridos em razão de sua participação, seu direito de indenização será garantido, mediante comprovação legal.

Informamos que a pesquisa não irá interferir no tratamento já programado para seu problema de saúde. Os produtos utilizados nesta investigação já fazem parte da rotina do hospital e, caso haja qualquer problema relacionado à sua utilização, será tratado seguindo a rotina já empregada pela instituição.

$\mathrm{O}$ (a) Sr(a) será esclarecido(a) sobre a pesquisa a respeito de qualquer aspecto que desejar. O(a) Sr(a) é livre para recusar-se a participar, retirar seu consentimento ou interromper a participação a qualquer momento. A sua participação é voluntária e a recusa em participar não acarretará qualquer penalidade, perda de benefícios ou descontinuidade de sua assistência. 
Fernanda de Oliveira Andrade

Será garantido em qualquer etapa do estudo, o seu acesso aos profissionais responsáveis pela pesquisa para esclarecimento de eventuais dúvidas. O principal investigador é Fernanda de Oliveira Andrade que pode ser encontrado no endereço Rua Amintas de Barros, 531 - Centro - Curitiba/PR, telefones (43) 9090 999935-2615 ou (41) 9090 3206-9970, ou pelo e-mail: fernanda_andrade@usp.br. Se você tiver alguma consideração ou dúvida sobre a ética da pesquisa, entre em contato com o Comitê de Ética em Pesquisa (CEP) - Endereço: Av. Dr. Enéas de Carvalho Aguiar, 419 - Cerqueira Cesar - São Paulo/SP CEP - 05403-000, telefone (11) 3061-7544, ou pelo e-mail: edipesq@usp.br, ou com o Comitê de Ética em Pesquisa (CEP) da instituição coparticipante - Endereço: Rua General Carneiro, 181, - Alto da Glória - Curitiba/PR CEP - 80060-900, telefone (41) 3360-1041, ou pelo e-mail: cep@hc.ufpr.br.

Esta pesquisa atende todas as especificações da Resolução 466, de 12 de dezembro de 2012 que aprova as diretrizes e normas regulamentadoras de pesquisas envolvendo seres humanos. Este Termo de Consentimento Livre e Esclarecido deverá ser rubricado pelo(a) $\mathrm{Sr}(\mathrm{a})$ e por mim, nas suas duas páginas e assinado nas duas vias. $\mathrm{O}$ (a) $\mathrm{Sr}(\mathrm{a})$ receberá uma via do Termo de Consentimento Livre e Esclarecido assinada e rubricada por mim (pesquisador).

Acredito ter sido suficientemente informado a respeito das informações que li ou que foram lidas para mim, descrevendo o estudo intitulado "Infecção do sítio cirúrgico e o uso de toalhas impregnadas com gluconato de clorexidina $2 \%$ no pré-operatório da pele: ensaio clínico randomizado - estudo piloto".

Eu discuti com a Enf ${ }^{a}$ Fernanda de Oliveira Andrade sobre a minha decisão em participar nesse estudo. Ficaram claros para mim quais são os objetivos do estudo, os procedimentos a serem realizados, seus desconfortos e riscos, as garantias de confidencialidade e de esclarecimentos permanentes. Ficou claro também que minha participação é isenta de despesas e que tenho garantia do acesso a tratamento hospitalar quando necessário. Concordo voluntariamente em participar deste estudo e poderei retirar 0 meu consentimento a qualquer momento, antes ou durante o mesmo, sem penalidades ou prejuízo ou perda de qualquer benefício que eu possa ter adquirido, ou no meu atendimento neste Serviço.

Assinatura do pesquisador

Data 11

Assinatura do participante

Data / /

Rubrica do participante:

Rubrica do pesquisador: 
Fernanda de Oliveira Andrade

APÊNDICE E - Questionário de satisfação em relação ao produto

\begin{tabular}{|l|l}
\hline Paciente: & Registro:
\end{tabular}

1. Em geral, qual o grau de satisfação com o produto?

( ) Satisfeito

( ) Pouco satisfeito

( ) Insatisfeito

2. Você utilizaria este produto novamente, caso fosse necessário? Se não, explique o porquê?
( ) $\operatorname{Sim}$
( ) Não

3. O produto causou algum desconforto?
( ) $\operatorname{Sim}$
( ) Não

Qual (is)? Especifique a região afetada:

( ) Ressecamento de pele

( ) Coceira

( ) Vermelhidão

( ) Lesões

( ) Outros:

4. Você tem quaisquer outros comentários, perguntas, sugestões ou reclamações? 
Anexos 
Fernanda de Oliveira Andrade

ANEXOS

\section{ANEXO A - Instrumento de vigilância pós-alta}

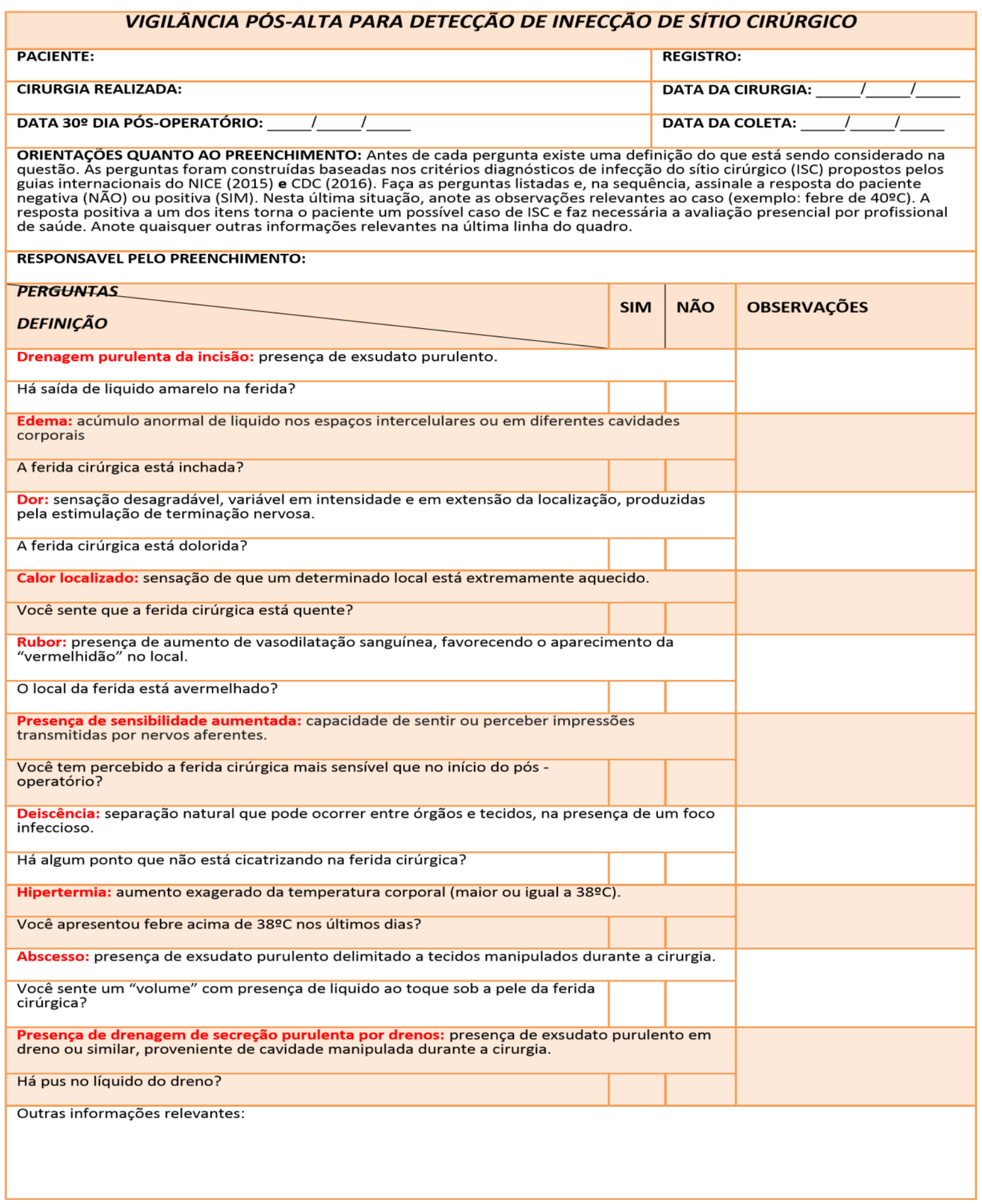


Fernanda de Oliveira Andrade

\title{
ANEXO B - Parecer do Comitê de Ética em Pesquisa
}

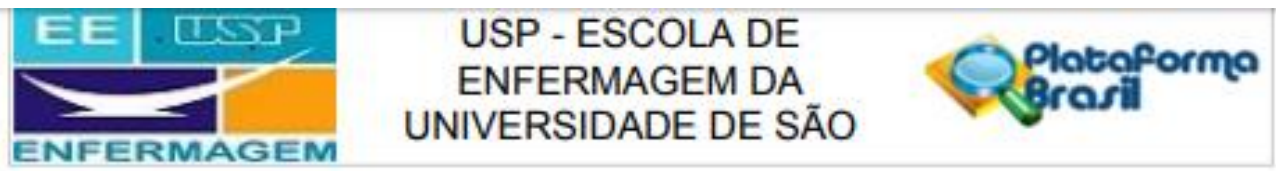

PARECER CONSUBSTANCIADO DO CEP

\section{DADOS DA EMENDA}

Título da Pesquisa: $O$ uso de toalhas impregnadas com clorexidina $2 \%$ no pré-operatório: prevençăo da infecçăo de sítio cirúrgico.

Pesquisador: Femanda de Oliveira Andrade

Área Temática:

Versăo: 2

CAAE: 65131617.5 .0000 .5392

Instituição Proponente: Escola de Enfermagem da USP

Patrocinador Principal: Financiamento Próprio

\section{DADOS DO PARECER}

Número do Parecer: 2.157.183

\begin{abstract}
Apresentaçāo do Projeto:
O projeto de pesquisa tem como finalidade a dissertaçăo de mestrado de Fernanda de Oliveira Andrade, sob orientaçăo da Professora Doutora Vanessa de Brito Poveda. Trata-se de estudo quantitativo, experimental, do tipo ensaio clínico randomizado (ECR), a ser realizado em um hospital universitário federal público, de nível terciário, destinado ao ensino, pesquisa e assistência, situado no estado do ParanáVerificará a contribuição do uso de toalhas impregnadas com clorexidina $2 \%$ (CHG) para a prevençâa da infecção de sítio cirúrgico (ISC) em pacientes submetidos à cirurgias eletivas do sistema digestório. Serăo formados dois grupos, compostos por 85 pacientes cada para obtençăo de um intervalo de confiança de $80 \%$, o grupo intervençăo (GI): pacientes que utilizarăo as toalhas impregnadas com CHG $2 \%$ para o banho pré-operatório, e o grupo controle (GC): pacientes que serâo submetidos ao banho pré-operatório, com CHG $2 \%$ convencional (liquida). A composiçăo aleatória dos grupos se dará por meio de sorteio, sem reposiçâo. de modo que cada individuo tenha a mesma chance de ser selecionado nos diferentes grupos (intervençăo e controle). Serâo incluidos no estudo pacientes com idade igual ou superior à 18 anos, alfabetizados. submetidos a cirurgias eletivas do sistema digestório, admitidos no mesmo dia do procedimento cirúrgico ou no máximo com trẻs dias de internação anteriores à
\end{abstract}

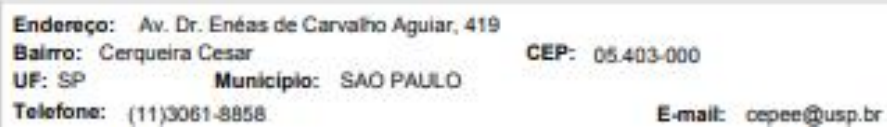




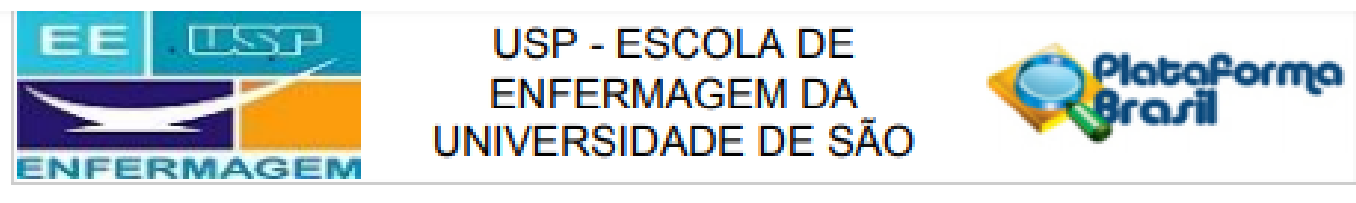

Continuaçso do Parecer. 2. 157. 183

cirurgia; ausência de processo infeccioso ou inflamatório em outro sitio e capacidade de seguir corretamente as instruọbes para o uso das toalhas impregnadas com CHG $2 \%$. Serăo excluídos os pacientes submetidos a cirurgias anteriores, em um periodo inferior a trinta dias, ou noventa dias quando implante de prótese: presença de lesర̄es de pele ou alergia conhecida à CHG $2 \%$; fazer uso diário de produtos que contenham antissépticos (cremes e/ou sabonetes líquidos ou em barra contendo gluconato de clorexidina, triclosan ou similares) na sua atividade diária; uso de antibióticos ou fármacos similares duas semanas antes e durante o período da coleta de dados. Realizar-se-á um estudo piloto com dois voluntários que se enquadrem nos critérios de inclusăo e exclusăo, para verificar a adequaçăo do procedimento de coleta e instrumentos da pesquisa, os mesmos nâo serâo incluidos na amostra da pesquisa. Nâo será permitido que os pacientes troquem de grupo após a alocaçăo.

No dia da cirurgia os pacientes do grupo experimental e controle serão questionados a respeito de sua opiniâo quanto à praticidade da utilizaçăo das toalhas impregnadas com CHG $2 \%$. Para a pesquisa dos potenciais casos de ISC a pesquisadora acompanhará pessoalmente os pacientes até a alta hospitalar em visitas no $3^{\circ}, 7^{\circ}, 15^{\circ} \mathrm{e} 30^{\circ}$ dias de internaçăo e, posteriormente à alta, no $15^{\circ}$ e $30^{\circ}$ dia, por meio de contato telefónico com o paciente utilizando instrumento de vigiláncia pós-alta em processo de validaçăo, ou ainda, caso

possivel, o acompanhará no retorno ambulatorial, para avaliar as condiçōes clínicas, e evoluçăo da ferida operatória, e possiveis sinais de ISC. Esclarece-se que todos os potenciais casos de ISC, identificados durante a internaçăo ou após a alta, serăo discutidos com a Comissăo de Controle de Infecção Hospitalar e a equipe cirúrgica responsável e encaminhados para tratamento, segundo a necessidade e trâmites correntes na Instituiçăo campo de estudo. Para análise dos dados será construido um banco de dados no software Microsft Excel, posteriormente os dados serão exportados para o software Statistical Package for the Social Sciences (SPSS). Os resultados serão analisados com auxilio de um profissional estatistico, as variáveis dicotômicas serâo avaliadas por meio do teste Qui-quadrado ou teste Fisher quando apropriado; as variáveis contínuas serão avaliadas por meio do teste $t$ de Student ou Mann Whitney quando apropriado; no modelo de regressão serăo selecionadas as variáveis que apresentarem p0,25 nas análises bivariadas. O nivel de significância delimitado será $=0,05$.

\section{Objetivo da Pesquisa:}

Objetivo Primário:

- Determinar a eficácia das toalhas impregnadas com CHG $2 \%$ comparadas ao banho pré-

Endereço: Av. Dr. Enéas de Carvalho Aguiar, 419 CEP: 05.403-000
Bairro: Cerqueira Cesar
$\begin{aligned} & \text { UF: SP } \\ & \text { Telefone: (11)3061-8858 }\end{aligned}$


Fernanda de Oliveira Andrade

USP - ESCOLA DE
ENFERMAGEM DA
UNIVERSIDADE DE SÃO

Continuaça do Parecer. 2. 157.183

operatório tradicional com CHG $2 \%$ convencional (líquida) na prevençăo da infecçẫo de sítio cirúrgico entre pacientes submetidos a cirurgias eletivas do sistema digestório.

Objetivos Secundários:

- Comparar as taxas de ISC entre os pacientes que utilizaram o banho tradicional e a aplicação das toalhas impregnadas com CHG 2\%;

- Correlacionar a ocorrência de ISC e as variáveis relacionadas ao paciente, procedimento e o tipo de banho/preparo pré-operatório da pele;

- Realizar um cálculo comparativo do custo de aquisição do material para o banho tradicional e a utilizaçăo das toalhas impregnadas com CHG $2 \%$;

- Determinar as dificuldades e facilidades referidas pelos pacientes na utilização das toalhas impregnadas com CHG $2 \%$.

\section{Avaliação dos Riscos e Beneficios:}

Considerando que o produto a ser utilizado é o mesmo para ambos os grupos, a proponente relata "risco minimo* relativo a diferença na sensaçăo de conforto quanto a utilizaçăo do produto em diferentes apresentaçôes, o que năo interferirá ou prejudicará a execuçăo e segurança do ato cirúrgico.

Como benefícios evidencia-se a possibilidade da descoberta de um método mais simples de preparo préoperatório da pele, em substituiçâo ao banho com agente antisséptico, com potencial para prevençăo da ISC.

\section{Comentários e Consideraçōes sobre a Pesquisa:}

O estudo tem potencial para evidenciar a maior eficácia do uso de toalhas impregnadas com CHG $2 \%$ no preparo pré-operatório da pele, em comparaçăo com o banho com CHG $2 \%$ convencional (líquida), na reduçăo da contagem microbiana da pele, e consequente na reduçăo da ISC.

\section{Consideraçōes sobre os Termos de apresentação obrigatória:}

Nada a declarar.

\section{Recomendações:}

Nada a declarar.

\section{Conclusōes ou Pendências e Lista de Inadequaçōes:}

Foi apresentada emenda relativa a "ALTERAÇĀO do critério de inclusăo, de cirurgias ELETIVAS do sistema digestório, para cirurgias eletivas POTENCIALMENTE CONTAMINADAS. A SOLICITAÇÃO DE

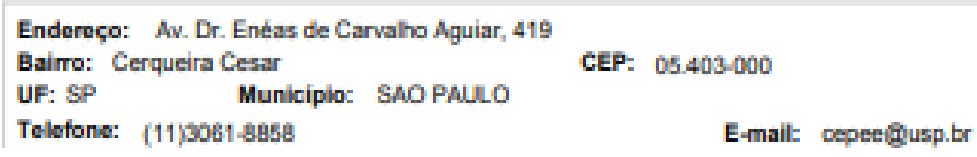


Fernanda de Oliveira Andrade

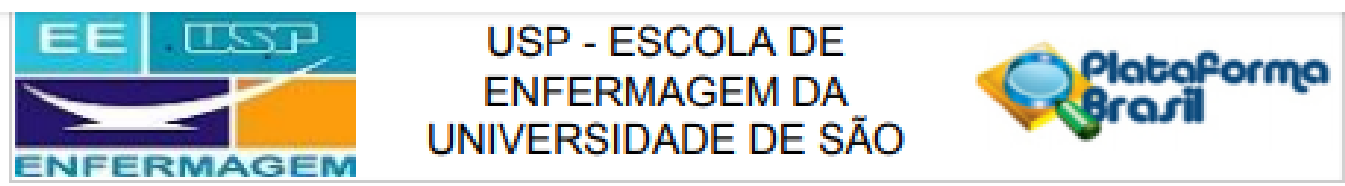

Contnuaço do Parecer. 2.157.183

ALTERAÇĂO PRETENDE AMPLIAR A OPÇĂO DE POTENCIAIS CANDIDATOS APTOS PARA A COLETA DE DADOS, devido ao curto período de tempo DISPONIVEL."

Consideraçōes Finais a critério do CEP:

- Este CEP informa a necessidade de registro dos resultados parciais e finais na Plataforma Brasil;

- Esta aprovaçăo năo substitui a autorizaçăo da instituição coparticipante, antes do início da coleta de dados.

Este parecer foi elaborado baseado nos documentos abaixo relacionados:

\begin{tabular}{|c|c|c|c|c|}
\hline Tipo Documento & Arquivo & Postagem & Autor & Situaçâo \\
\hline $\begin{array}{l}\text { Informaçóes Básicas } \\
\text { do Projeto }\end{array}$ & $\begin{array}{l}\text { PB_INFORMAÇOES_BASICAS_940156 } \\
\text { E1.pdf }\end{array}$ & $\begin{array}{c}16 / 06 / 2017 \\
16: 05: 10\end{array}$ & & Aceito \\
\hline $\begin{array}{l}\text { TCLE / Termos de } \\
\text { Assentimento / } \\
\text { Justificativa de } \\
\text { Ausência. }\end{array}$ & TCLE.docx & $\begin{array}{c}16 / 06 / 2017 \\
15: 08: 06\end{array}$ & $\begin{array}{l}\text { Fernanda de Oliveira } \\
\text { Andrade }\end{array}$ & Aceito \\
\hline $\begin{array}{l}\text { Projeto Detalhado / } \\
\text { Brochura } \\
\text { Investigador }\end{array}$ & Projeto_Detalhado.doc & $\begin{array}{c}16 / 06 / 2017 \\
15: 06: 09\end{array}$ & $\begin{array}{l}\text { Fernanda de Oliveira } \\
\text { Andrade }\end{array}$ & Aceito \\
\hline Cronograma & CRONOGRAMA_doCX & $\begin{array}{c}12 / 06 / 2017 \\
10: 44: 54 \\
\end{array}$ & $\begin{array}{l}\text { Fernanda de Oliveira } \\
\text { Andrade }\end{array}$ & Aceito \\
\hline Outros & ANEXO_A_docx & $\begin{array}{l}23 / 02 / 2017 \\
11: 55: 46\end{array}$ & $\begin{array}{l}\text { Fernanda de Oliveira } \\
\text { Andrade }\end{array}$ & Aceito \\
\hline Outros & APENDICE_Edocx & $\begin{array}{c}23 / 02 / 2017 \\
11: 55: 29\end{array}$ & $\begin{array}{l}\text { Fernanda de Oliveira } \\
\text { Andrade }\end{array}$ & Aceito \\
\hline Outros & APENDICE_D.docx & $\begin{array}{c}23 / 02 / 2017 \\
11: 55: 10\end{array}$ & $\begin{array}{l}\text { Fernanda de Oliveira } \\
\text { Andrade }\end{array}$ & Aceito \\
\hline Outros & APENDICE_C.docx & $\begin{array}{c}23 / 02 / 2017 \\
11: 54: 48\end{array}$ & $\begin{array}{l}\text { Fernanda de Oliveira } \\
\text { Andrade }\end{array}$ & Aceito \\
\hline Outros & Apendice_A.docx & $\begin{array}{c}23 / 02 / 2017 \\
11: 53: 43 \\
\end{array}$ & $\begin{array}{l}\text { Fernanda de Oliveira } \\
\text { Andrade }\end{array}$ & Aceito \\
\hline Outros & Declaracao.jpg & $\begin{array}{c}21 / 02 / 2017 \\
18-52: 59\end{array}$ & $\begin{array}{l}\text { Fernanda de Oliveira } \\
\text { Andrade }\end{array}$ & Aceito \\
\hline Orçamento & Orcamento.docx & $\begin{array}{c}21 / 02 / 2017 \\
18: 48: 06\end{array}$ & $\begin{array}{l}\text { Fernanda de Oliveira } \\
\text { Andrade }\end{array}$ & Aceito \\
\hline Folha de Rosto & Folha.pdf & $\begin{array}{c}21 / 02 / 2017 \\
18: 34: 43\end{array}$ & $\begin{array}{l}\text { Fernanda de Oliveira } \\
\text { Andrade }\end{array}$ & Aceito \\
\hline
\end{tabular}

Situaçāo do Parecer:

Aprovado

Endereço: Av. Dr. Enéas de Carvalho Aguiar, 419

Bairro: Cerqueira Cesar

UF: SP Municipio: SAOPAULO

CEP: 05.403 .000

Telefone: (11)3061-8858

E-mail: cepee@usp.br 
Fernanda de Oliveira Andrade

USP - ESCOLA DE
ENFERMAGEM DA
UNIVERSIDADE DE SÃO

Continuaçlo do Parecer: 2.157.183

Necessita Apreciação da CONEP:

Não

SAO PAULO, 05 de Julho de 2017

Assinado por:

Marcelo José dos Santos

(Coordenador) 